Florida International University FIU Digital Commons

$11-22-2000$

\title{
The dissociative recombination of the helium molecular ion the observed final products
}

Luminita Coman

Florida International University

DOI: $10.25148 /$ etd.FI14060883

Follow this and additional works at: https://digitalcommons.fiu.edu/etd

Part of the Physics Commons

\section{Recommended Citation}

Coman, Luminita, "The dissociative recombination of the helium molecular ion the observed final products" (2000). FIU Electronic Theses and Dissertations. 2412.

https://digitalcommons.fiu.edu/etd/2412

This work is brought to you for free and open access by the University Graduate School at FIU Digital Commons. It has been accepted for inclusion in FIU Electronic Theses and Dissertations by an authorized administrator of FIU Digital Commons. For more information, please contact dcc@fiu.edu. 
FLORIDA INTERNATIONAL UNIVERSITY

Miami, Florida

THE DISSOCIATIVE RECOMBINATION OF THE HELIUM MOLECULAR ION THE OBSERVED FINAL PRODUCTS

A thesis submitted in partial fulfillment of the

requirements for the degree of

MASTER OF SCIENCE

in

PHYSICS

by

Luminita Coman 
To: Dean Arthur W. Herriott

College of Arts and Science

This thesis, written by Luminita Coman, and entitled The Dissociative Recombination of the Helium Molecular Ion The Observed Final Products, having been approved in respect to style and intellectual content, is referred to you for judgment.

We have read this thesis and recommend that it be approved.

John T. Landrum

Yifu Zhu

Xuewen Wang

Kenneth A. Hardy, Major Professor

Date of Defense: November 22, 2000

The thesis of Luminita Coman is approved.

Dean Arthur W. Herriott College of Arts and Sciences

Interim Dean Samuel S. Shapiro

Division of Graduate Studies

Florida International University, 2000 


\section{DEDICATION}

Dedicated in memory of my mother. 


\section{ACKNOWLEDGMENTS}

This work would not have been possible without support from many people. First I would like to give special thanks to Dr. Kenneth A. Hardy for his patience, encouragement, and advice throughout my graduate education. In addition, I would like to thank my committee members: Dr. Xuewen. Wang, Dr. Yifu Shu, and Dr. John T. Landrum, for their constructive criticism of my thesis.

I am very grateful to Carlos Orta for the mechanical support which he provided. In addition, I would like to thank Libni Simons and Miguel Faxas who assisted in the data acquisition and analysis.

I am very grateful to all the faculty and staff of the Florida Iinternational University Physics Department for their support in my education. 
THE DISSOCIATIVE RECOMBINATION OF THE HELIUM MOLECULAR ION THE OBSERVED FINAL PRODUCTS

\author{
by \\ Luminita Coman \\ Florida International University, 2000 \\ Miami, Florida \\ Professor Kenneth Hardy, Major Professor
}

Dissociative recombination reaction has been studied theoretically and experimentally for about four decades. Because of the complexity of this process there is not yet a definite agreement between theory and experiment. In this work, dissociative recombination (DR) of helium molecular ion in thermal plasma was studied using Time of Flight (TOF) spectroscopy. This method allowed the identification of the final atom states products of DR. We found the following final products of the DR of the molecular ion:

$\operatorname{He}\left({ }^{3} S ; 1 s 3 s\right), \operatorname{He}\left({ }^{1} S ; 1 s 3 s\right), \operatorname{He}\left({ }^{3} P ; 1 s 3 p\right), \operatorname{He}\left({ }^{3} D ; 1 s 3 d\right), \operatorname{He}\left({ }^{1} D ; 1 s 3 d\right), \operatorname{He}\left({ }^{1} P ; 1 s 3 p\right)$, $\mathrm{He}\left({ }^{3} \mathrm{~S} ; 1 \mathrm{~s} 2 \mathrm{~s}\right), \operatorname{He}\left({ }^{1} \mathrm{~S} ; 1 \mathrm{~s} 2 \mathrm{~s}\right)$ and possibly $\operatorname{He}\left({ }^{1} \mathrm{~S} ; 1 \mathrm{~s}^{2}\right)$. Results similar to ours were obtained in experiments done using optical methods. The actual theoretical models predicts only $n=2$ manifold states. Further theoretical modeling for this complex process is required. 


\section{TABLE OF CONTENTS}

CHAPTER

PAGE

I. Introduction 1

II. History of Dissociative Recombination (DR) process 4

III. Theory

III.1 Formation of the helium molecular ion 6

III.2 The curve crossing model for DR reaction $\quad 8$

$\begin{array}{ll}\text { III.3 Rotation and vibration of diatomic molecules } & 11\end{array}$

$\begin{array}{lr}\text { III.4 Final atomic product states identification } & 18\end{array}$

III.5 Multichannel Quantum Defect Thery (MCQDT) description of DR 20

III.6 Cross sections for DR reaction calculated by MCQDT 26

$\begin{array}{ll}\text { IV. Apparatus } & 32\end{array}$

V. Time of Flight Analysis $\quad 38$

VI. Data interpretation $\quad 41$

VII. Experimental results $\quad 45$

VIII. Comments 53

$\begin{array}{ll}\text { IX. Conclusions } & 55\end{array}$

References $\quad 56$

$\begin{array}{ll}\text { Appendices } & 58\end{array}$ 


\section{LIST OF TABLES}

TABLE

PAGE

1. The possible final products of DR of the $\mathrm{He}_{2}{ }^{+}(\mathrm{v}, \mathrm{J})$ rovibrational excited molecular ion

2. The theoretical and experimental velocities of the product atoms yielded in the DR process of the $\mathrm{He}_{2}{ }^{+}$from various rovibrational states to the $\mathrm{He}$ $\left({ }^{3} \mathrm{~S} ; 1 \mathrm{~s} 3 \mathrm{~s}\right)$ atomic level at $183236.9 \mathrm{~cm}^{-1}$.

3. The theoretical and experimental velocities of the product atoms yielded in the DR process of the $\mathrm{He}_{2}{ }^{+}$from various rovibrational states to $\mathrm{He}\left({ }^{1} \mathrm{~S}\right.$; $1 \mathrm{~s} 3 \mathrm{~s})$ the atomic level at $184864.9 \mathrm{~cm}^{-1}$.

4. The expected and experimental velocities of the product atoms yielded in the DR process of helium molecular ion from various rovibrational states to the $\mathrm{He}\left({ }^{3} \mathrm{P} ; 1 \mathrm{~s} 3 \mathrm{p}\right)$ atomic level at $185564.6 \mathrm{~cm}^{-1}$.

5. The theoretical and experimental velocities of the product atoms yielded in the DR process of helium molecular ion from various rovibrational states to the $\mathrm{He}\left({ }^{3} \mathrm{D} ; 1 \mathrm{~s} 3 \mathrm{~d}\right)$ atomic level at $186101.7 \mathrm{~cm}^{-1}$.

6. The theoretical and experimental velocities of the product atoms yielded in the DR process of helium molecular ion from various rovibrational states to the $\mathrm{He}\left({ }^{1} \mathrm{D} ; 1 \mathrm{~s} 3 \mathrm{~d}\right)$ atomic level at $186105.1 \mathrm{~cm}^{-1}$.

7. The velocities of the product atoms yielded in the DR process of the $\mathrm{He}_{2}{ }^{+}$ to the $\mathrm{He}\left({ }^{1} \mathrm{P} ; 1 \mathrm{~s} 3 \mathrm{p}\right)$ atomic level at $186209.5 \mathrm{~cm}^{-1}$.

8. The additional lines observed using the short flight path. 


\section{LIST OF FIGURES}

FIGURE

PAGE

1. Potential energy curve crossings as a function of internuclear separation

2. Schematic representation of the vibrational and rotational levels in a molecule.

3. Potential-energy curves involved in DR of $\mathrm{He}_{2}{ }^{+}$with slow electrons

4. DR cross section (isotopic effect) for the direct process for $\mathrm{v}=0, \mathrm{~J}=0$ and $\mathrm{v}=4, \mathrm{~J}=0$ initial state

5. DR cross section for the global (direct plus indirect) process, starting from $\mathrm{v}=0 \mathrm{~J}=0$ initial level in a smaller range of energies $(0-0.2) \mathrm{meV}$

6. Effect of the initial vibrational excitation. Total DR cross section (summed over the three lowest dissociative states for $\mathrm{v}=0$ and $\mathrm{v}=4$ initial vibrational levels $(\mathrm{J}=0)$ of the molecular ion

7. The molecular beam apparatus

8. The metastable atom source glow discharge tube with a block diagram 36 for the electronics

9. Detector geometry

10. Electronic System for Time-of-Flight Analysis

11. Energy Resolution for different lengths of the flifht paths

12. A typical DR spectrum 


\section{INTRODUCTION}

Dissociative Recombination of diatomic molecular ions with electrons is of great interest because of the importance of the process in many regions of Earth's ionosphere, in laboratory plasma, gaseous lasers and more generally in chemical processes. The Dissociative Recombination (DR) of helium molecular ions is of particular interest because of "the terrestrial helium problem" [1] which refers to the apparent imbalance between the atmospheric sources and sinks of helium. The main source of atmospheric helium is the radioactive decay in the natural radioactive series of uranium and thorium in the mantle and crust of the Earth, followed by degassing into the atmosphere. The degassing flux density, averaged over the Earth's surface, has been estimated to be approximately $0.9-1.9 \times 10^{6} \mathrm{~cm}^{-2} \mathrm{~s}^{-1}[2]$. At this degassing flux density it would only take about $10^{6}$ years to supply the atmosphere with its present amount of helium [3]. One process that can remove helium from the atmosphere is the DR of the helium molecular ions to totally ground state products. The DR atomic products would have velocities greater than the escape velocity from Earth $(22,000 \mathrm{~m} / \mathrm{s})$ and DR to totally ground state products might be responsible for the loss of helium from the Earth's atmosphere.

The dissociative recombination process has been studied for many years, both experimentally and theoretically. Because of the complexity of this process, there has not yet been a definitive comparison of theory and experiment. In calculations, the 
major problems arise because of the lack of knowledge about the energy and lifetimes of the intermediate molecular states through which the recombination proceeds, and from uncertainty about the role of vibrationally excited Rydberg states in the recombination process. The data in the literature are contradictory, and it has not been possible to identify reliably even the vibrational states of the ions involved and the states of the excited helium atoms which are formed as a result of the recombination [4]. A quantitative comparison between theory and experiment will not be possible until measurements can be performed for ions in a single vibrational state, or the vibrational states can be identified [5].

The method used here to study DR allows the simultaneous identification of the initial state of the molecular ion which undergoes DR together with the states of the two final atom products. In chapter III of this thesis a general theory of DR is presented. The method used in this thesis to study Dissociative Recombination of helium molecular in thermal plasma is Time-of-Flight (TOF) spectroscopy. The apparatus used and the Time of Flight analysis are described in chapters IV and V. Time-of-flight (TOF) spectroscopy is used to measure the velocities of the metastable atoms yielded by the DR of helium molecular ions. The velocities are obtained by measuring the time of flight for the atoms for the given path length. Using various source conditions (pressure, discharge voltage, discharge current, magnetic fields) the population of the vibrational and rotational states of the molecular ions is varied and different atomic final product states are observed. 
For the present work approximately 400 spectra have been collected and analyzed.

The fits to the experimental data were done using preexistent basic fitting programs.

In chapter VI the treatment of the data is explained. In chapter VII experimental results are presented and in chapter VIII the results are discussed. 


\section{HISTORY OF DISSOCIATIVE RECOMBINATION (DR)}

It has been observed that the recombination rates for diatomic molecular ions of rare gases with slow electrons is about three orders of magnitude bigger than the recombination rate for atomic ions [6]. The recombination rates for molecular ions of rare gases (except helium) have been found to be in the range $10^{-6}-10^{-7} \mathrm{~cm}^{3} / \mathrm{s}$ at 300 K. Bates [7] explained this result in terms of Dissociative Recombination of molecular ions with slow electrons. In this process the slow electron is captured by the molecular ion and a neutral excited molecule is formed. For certain energies of the electron and molecular ion the excited molecule breaks up into the component atoms.

Some of the features of the DR process have been demonstrated by the study of the emission spectra of a plasma afterglow. This has revealed that excited atoms are formed in the recombination. By studying the Doppler broadening of the spectral lines Connor and Biondi have measured the kinetic energy of the radiating atoms and found it to be much greater than the expected thermal energy [ 8].

The electron- $\mathrm{He}_{2}{ }^{+}$molecular ion recombination remains the one exception where the diatomic recombination rate is orders of magnitude less $\left(\sim 10^{-10} \mathrm{~cm}^{3} / \mathrm{s}\right.$ at $\left.300 \mathrm{~K}\right)$. This is explained by the fact that no repulsive potential curves pass in the vicinity of the $\mathrm{He}_{2}{ }^{+}$ground state potential function. The intersection point between the lowest dissociative curve and the ion ground state curve is situated well above the minimum 
of the potential well, between $v=2$ and $v=3$ outer turning points[9]. At room temperature the population of the vibrational levels $v=2,3$ is small and consequently the recombination rate very small.

A method which has been widely used previously to study DR was based on comparing the time evolution of the densities of atomic ions and molecular ions obtained by a mass-spectrometry technique, and by studying the intensities of atomic lines and molecular bands in a decaying plasma. This method is not appropriate for studying this reaction since $\mathrm{He}_{2}{ }^{+}$vibrationaly excited ions participate in the process of DR in weakly ionized plasma, and mass-spectrometer detectors are not sensitive to the vibrational state of the molecular ion. Other methods used are optical methods, specifically, methods for analyzing the emission of the decaying plasma. In this case, once again, there is no information about the vibrational and rotational states of the molecular ion since transitions between these states are forbidden.

Due to the complexity of the phenomena in a plasma afterglow only controversial results could be obtained. Calculations of the cross section for the DR of helium molecular ion were done recently [10] using Multichannel Quantum Defect Theory (MCQDT) applied to the molecular ion. In the present work a qualitative comparison of our experimental result with those of $[10]$ is presented. 


\section{III.1 FORMATION OF THE HELIUM MOLECULAR ION}

The molecular ion, $\mathrm{He}_{2}{ }^{+}$, is formed through various processes such as: (1) associative ionization (AI), (2) three body conversion of the atomic ion to the molecular ion. It has been shown that the second process is significant only at relatively high pressures[11]. For the formation of $\mathrm{He}_{2}{ }^{+}$in conditions of very low pressures the main mechanism is the associative ionization $(\mathrm{AI})$ reaction $[12,13]$ :

$H e\left(1 s^{2}\right)+H e^{*}(1 s y) \rightarrow H e_{2}^{+}(J, v)+e^{-}$

The excited helium atoms involved in reaction (III.1.1) are produced by electron impact excitation process:

$$
H e\left(1 s^{2}\right)+e^{-} \rightarrow H e^{*}(1 s y)+e^{-}
$$

Due to energy conservation, the associative ionization reaction occurs only for excited helium atom states within 1 or $2 \mathrm{eV}$ of ionization. It does not occur except when $\mathrm{y}$ ((III.1.1) is a Rydberg state with $n>3$. The experimental evidence suggests that the effect becomes increasingly stronger for higher $\mathrm{n}[11]$.

Theoretical considerations of the shapes of potential curves of the excited dissociative states of $\mathrm{He}_{2}{ }^{* *}$ indicate that $\mathrm{DR}$ of $\mathrm{He}_{2}{ }^{+}$is impossible except for higher vibrational states [9]. It is clear that the population distribution of the vibrational levels of $\mathrm{He}_{2}{ }^{+}$, and 
the vibrational relaxation process studied in a plasma are vital to understanding the recombination mechanism.

Some of the atomic excited states of helium may be populated to a large extent due to the electron-impact excitation process. The population of the excited atomic states are varied by the collision excitation transfer process. In this reaction a ground state helium atom collides with an excited rare gas atom and the result is an helium atom excited into a different state. At pressures in the range of those used in our source this type of reaction should have a very low cross section [13]. Then, the main mechanism that leads to the formation of helium molecular ion in pressure conditions of the source discharge (tens of mtorr) is the associative ionization process. 


\section{III.2 THE CURVE CROSSING MODEL FOR DISSOCIATIVE \\ RECOMBINATION (DR) OF $\mathrm{HE}_{2}^{+}$}

$\mathrm{DR}$ of $\mathrm{He}_{2}{ }^{+}$with an electron can be considered in terms of the formation and dissociation of a doubly excited state of the $\mathrm{He}_{2}$ molecule which proceeds through the following two reaction mechanisms:

$$
\begin{aligned}
& e^{-}+\mathrm{He}_{2}^{+} \rightarrow \mathrm{He}_{2}^{* *} \rightarrow \mathrm{He}(1 s)+\mathrm{He}^{*}(n l) \\
& e^{-}+\mathrm{He}_{2}^{+} \rightarrow \mathrm{He}_{2}^{*} \rightarrow H e_{2}^{* *} \rightarrow H e(1 s)+H e^{*}\left(n^{\prime} l\right)
\end{aligned}
$$

where $\mathrm{He}(1 \mathrm{~s})$ denotes the ground state helium atom and $\mathrm{He}(\mathrm{nl})$ stands for the helium excited atom, $\mathrm{n}$ being the principal quantum number and $\mathrm{l}$ the orbital quantum number. Both mechanisms involve the formation of a doubly excited Dissociative state $\mathrm{He}_{2}{ }^{* *}$ of the neutral molecule after which dissociation yields the atomic products $\mathrm{He}$ and $\mathrm{He}^{*}$.

Viewed in the framework of Born-Oppenheimer separation of nuclear and electronic motion, the DR reaction occurs by means of excitation of an electron of $\mathrm{He}_{2}{ }^{+}$with simultaneous capture of the incident electron. The excitation of the core electron destroys the molecular bound. Capture of an electron by a molecular ion can proceed by excitation of nuclear motion as well as by excitation of a bound electron.

Due to small energy differences involved in vibrational or rotational transitions only very low energy electrons can be captured and these into very weakly bound final states (intermediate excited states of the molecule). 
The first reaction is called 'direct' DR. If the nuclei are forced apart sufficiently before an electron is emitted by autoionization, the molecule can dissociate, retaining the incident electron. In the 'indirect' DR process (III.2.2) there is an intermediate step corresponding to electron capture in a Rydberg level $\mathrm{He}_{2} *$ associated with a vibrationally excited state of the initial ion $\mathrm{He}_{2}{ }^{+}$. In this process the capture of the electron is caused by the transfer of its energy either to electronic or nuclear motion (vibration or rotation) leading to an excited Rydberg state of the molecule. Electronic excitation of the molecular ion core is not usually considered as competitive although it is an open channel and is known to dominate in electron-atomic ion recombination. The excitation of nuclear motion of the recombining ion is most likely to be the dominant channel in the molecular analogue.

In figure 1.a and 1.b are shown the direct DR process and the indirect DR process, respectively [26].

Because the potential energy curves of the initial molecular ion states and the intermediate Rydberg states are very similar, any repulsive state of the molecule which can cause direct recombination will also lead to pre-dissociation of the intermediate states in indirect recombination. 

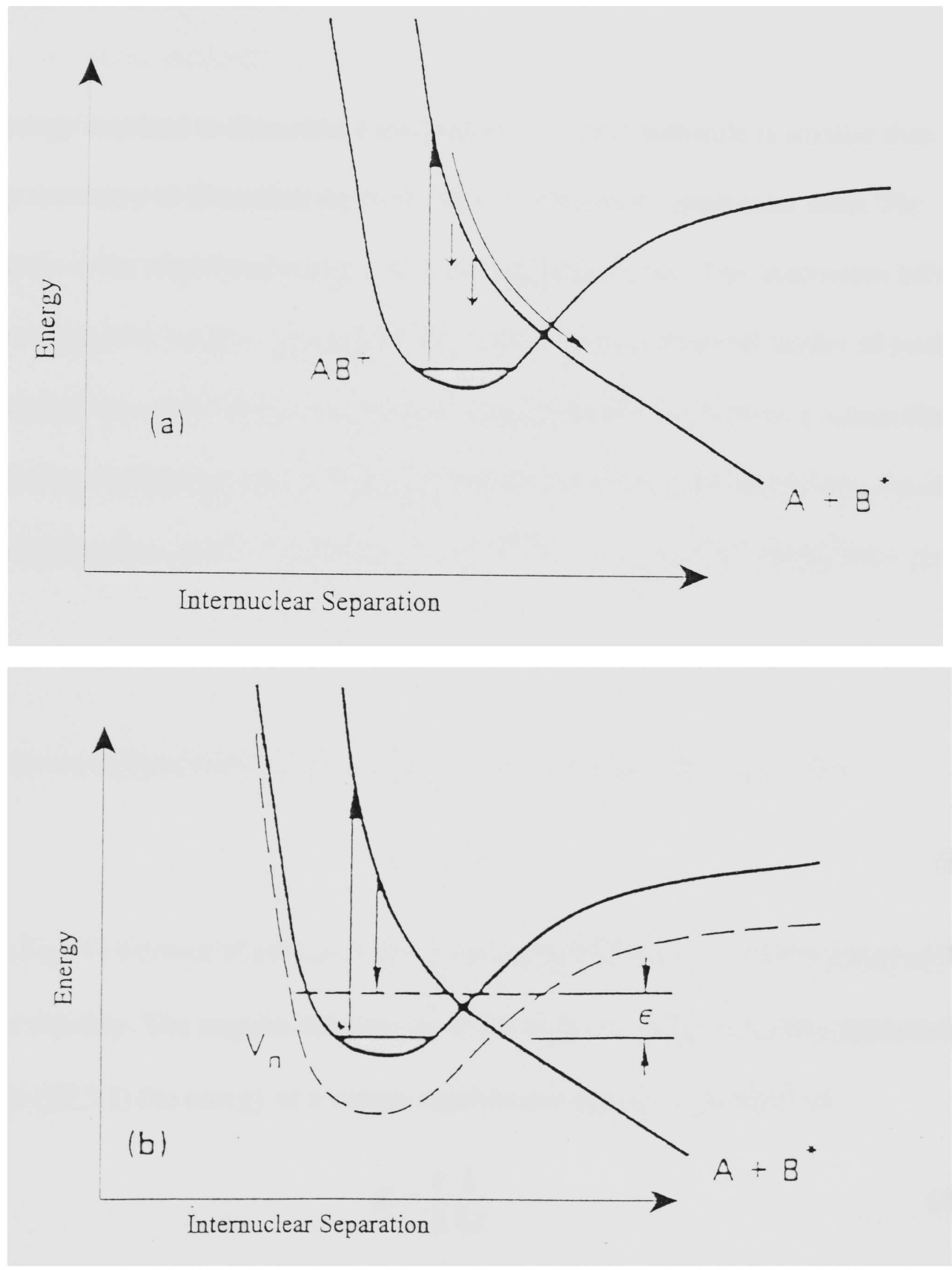

Figure 1

Potential energy curve crossings as a function of internuclear separation; (a) shows the direct process and (b) shows the indirect process. 


\section{III.3 ROTATION AND VIBRATION OF DIATOMIC MOLECULES}

The energy required to dissociate a rovibrational excited molecule is smaller than the energy necessary to dissociate the $(\mathrm{v}=0, \mathrm{~J}=0)$ rovibrational molecular state. The difference is the vibrational energy plus the rotational energy. The discussion below follows that given by [25]. For a diatomic molecule two additional modes of motion, which do not occur for atoms, are possible: the molecule can rotate as a whole about an axis passing through the center of mass and perpendicular to the line joining the nuclei (internuclear axis), and the atoms can vibrate relative to each other along the internuclear axis.

In classical mechanics the energy of rotation $\mathrm{E}$ of a rigid body is given by :

$$
E=\frac{1}{2} I \omega^{2}
$$

where: $I$ is the moment of inertia of the system about the axis of rotation and $\omega$ id the angular velocity. The angular momentum of the system is given by $\mathrm{L}=\mathrm{I} \omega$. Introducing this into (III.3.1) the energy of a simple rigid rotator may be expressed as:

$$
E=\frac{1}{2} \frac{L}{2 I}^{2}
$$

The Schrödinger equation solutions are single-valued, finite and continuous only for certain eigenvalues values $\mathrm{E}$ :

$$
E=\frac{h^{2} J(J+1)}{8 \pi^{2} \mu r^{2}}=\frac{h^{2} J(J+1)}{8 \pi^{2} I}
$$


where: the rotational quantum number $\mathrm{J}$ can take the integral values $0,1,2, \ldots$;

$\mu$ is the reduced mass of the molecule;

$r$ is the distance between the two atoms in the molecule.

The simplest possible assumption about the form of the vibrations in a diatomic molecule is that each atom moves toward or away from the other in simple harmonic motion, that is, that the displacement from the equilibrium position is a sine function of the time. Such a motion of the two atoms can easily be reduced to the harmonic vibration of a single mass point about an equilibrium position, that is to the model of the harmonic oscillator. The restoring force exerted by the two atoms of a molecule on each other is, at least approximately proportional to the change of internuclear distance. The harmonic oscillator equation becomes:

$$
\mu \frac{d^{2}\left(r-r_{e}\right)}{d t^{2}}=-k\left(r-r_{e}\right)
$$

where $\mu$ is the reduced mass of the two atoms of the molecule and

$\left(\mathrm{r}-\mathrm{r}_{\mathrm{e}}\right)$ is the change in of the internuclear distance from its equilibrium value.

Since the force is negative, the potential energy $\mathrm{V}$ for the harmonic oscillator is:

$$
V=\frac{1}{2} k\left(r-r_{e}\right)^{2}
$$

If we assume the potential energy of the two nuclei to be given by (III.3.4), the Schrödinger equation solutions that are single valued, finite, continuous and vanish at infinity exist for values of E given by:

$$
E(v)=\frac{h}{2} \sqrt{\frac{k}{\mu}}\left(v+\frac{1}{2}\right)=h v_{o s c}\left(v+\frac{1}{2}\right)
$$




$$
\text { where: } v_{o s c}=\frac{1}{2 \pi} \sqrt{\frac{k}{\mu}} \text { is the vibrational frequency of the molecule. }
$$

The vibrational quantum number $\mathrm{v}$ can take only integral values $0,1,2,3, \ldots$

If we transform energy values to term values (dividing by hc), we obtain for the vibrational term:

$$
G(v)=\omega\left(v+\frac{1}{2}\right)
$$

$\omega$ is the vibrational frequency measured in $\mathrm{cm}^{-1}$.

The equation (III.3.4) for the potential is not accurate to describe the molecule. When the atoms are at a great distance from each other, the attractive force is zero and the potential energy has a constant value. As a first approximation of the actual potential energy function of the molecule a cubic term is added:

$$
U=f\left(r-r_{e}\right)^{2}-g\left(r-r_{e}\right)^{3}
$$

Here the coefficient $g$ is very much smaller than $\mathrm{f}$. This function gives a better approximation for small values $\left(r-r_{e}\right)$. When this form of the potential energy is used in the Schrödinger equation, the energy values of the anharmonic oscillator are given by:

$$
E v=h c \omega_{e}\left(v+\frac{1}{2}\right)-h c \omega_{e} x_{e}\left(v+\frac{1}{2}\right)^{2}+h c \omega_{e} y_{e}\left(v+\frac{1}{2}\right)^{3}+\ldots
$$

The corresponding term values in wave number units, are given by:

$$
G(v)=\omega_{e}\left(v+\frac{1}{2}\right)-\omega_{e} x_{e}\left(v+\frac{1}{2}\right)^{2}+\omega_{e} y_{e}\left(v+\frac{1}{2}\right)^{3}+\ldots
$$

where: $\omega_{e}, \omega_{e} x_{e}, \omega_{e} y_{e}$ are constants. 
It is obvious that the molecule cannot be a strictly rigid rotator when it is also able to carry out vibrations in the direction of the line joining the two nuclei. Therefore a better model is given by a nonrigid rotator (a rotating system consisting of two mass points which are not connected by a massless rigid bar but by a massless spring). The energy formula for the nonrigid rotator is given by:

$$
E=\frac{h^{2}}{8 \pi^{2} \mu r_{e}^{2}} J(J+1)-\frac{h^{4}}{32 \pi^{4} \mu^{2} r_{e}^{6} k} J^{2}(J+1)^{2}+\ldots
$$

where: $k=4 \pi^{2} \omega^{2} c^{2} \mu$

The rotational term values are found to be:

$$
F(J)=B J(J+1)-D J^{2}(J+1)^{2}+H J^{3}(J+1)^{3}+\ldots
$$

where the rotational constant $\mathrm{D}$ is much smaller than $\mathrm{B}$, and $\mathrm{H}$ is much smaller than $\mathrm{D}$. So far we have regarded the rotation and the vibration of the molecule separately. However, it seems natural to assume that rotation and vibration can take place simultaneously. The model that should be considered is the rotating oscillator. If we could neglect the interaction of vibration and rotation, the energy of the vibrating rotor would be the sum of the vibrational energy of the anharmonic oscillator (III.3.7a) and the rotational energy of the nonrigid rotator (III.3.8a). We must take into consideration the fact that during the vibration the internuclear distance and consequently the moment of inertia and the rotational constant B are changing. Since the period of vibration is very small compared to the period of rotation, it seems plausible to use a mean B value for the rotational constant in the vibrational state considered:

$$
B_{v}=\frac{h}{8 \pi^{2} c \mu}\left[\overline{\frac{1}{r^{2}}}\right]
$$


where $\left[\overline{\frac{1}{r^{2}}}\right]$ is the mean value of $1 / \mathrm{r}^{2}$ during the vibration.

It is to be expected that $B_{v}$ will be somewhat smaller than the constant $B_{e}$, which corresponds to the equilibrium separation $r_{e}$, since with increasing vibration, because of anharmonicity, the mean nuclear separation will be greater. The value of $B_{e}$ is given by:

$$
B_{e}=\frac{h}{8 \pi^{2} c \mu_{e}} \frac{1}{r_{e}^{2}}
$$

A first approximation (usually satisfactory) gives $B_{v}$ as:

$$
B_{v}=B_{e}-\alpha_{e}\left(v+\frac{1}{2}\right)+\ldots
$$

Here $\alpha_{\mathrm{e}}$ is a constant which is small compared to $\mathrm{B}_{\mathrm{e}}$ since the change in the internuclear distance by the vibration is small compared to the internuclear distance itself.

In a similar manner, a mean rotational constant $D_{v}$, must be used for the vibrational state $v$, where:

$$
D_{v}=D_{e}+\beta_{e}\left(v+\frac{1}{2}\right)+\ldots
$$

Here $\beta_{e}$ is small compared to $D_{e}$ which refers to a completely vibrationless state:

$$
D_{e}=\frac{4 B_{e}^{3}}{\omega_{e}^{2}}
$$

We obtain, accordingly, for the rotational energy in a given vibrational level, in wave number units $\left(\mathrm{cm}^{-1}\right)$ :

$$
F_{v}(J)=B_{v} J(J+1)-D_{v} J^{2}(J+1)^{2}+\ldots
$$


By taking into consideration the interaction of vibration and rotation, in the way described above, we obtain for the energy of a vibrating rotator $\left(\right.$ in $\mathrm{cm}^{-1}$ ):

$$
T=G(v)+F_{v}(J)=\omega_{e}\left(v+\frac{1}{2}\right)-\omega_{e} x_{e}\left(v+\frac{1}{2}\right)^{2}+\ldots+B_{v} J(J+1)-D_{v} J^{2}(J+1)^{2}+\ldots
$$

A schematic representation of the vibrational and rotational levels in a molecule is presented in Figure 2. 


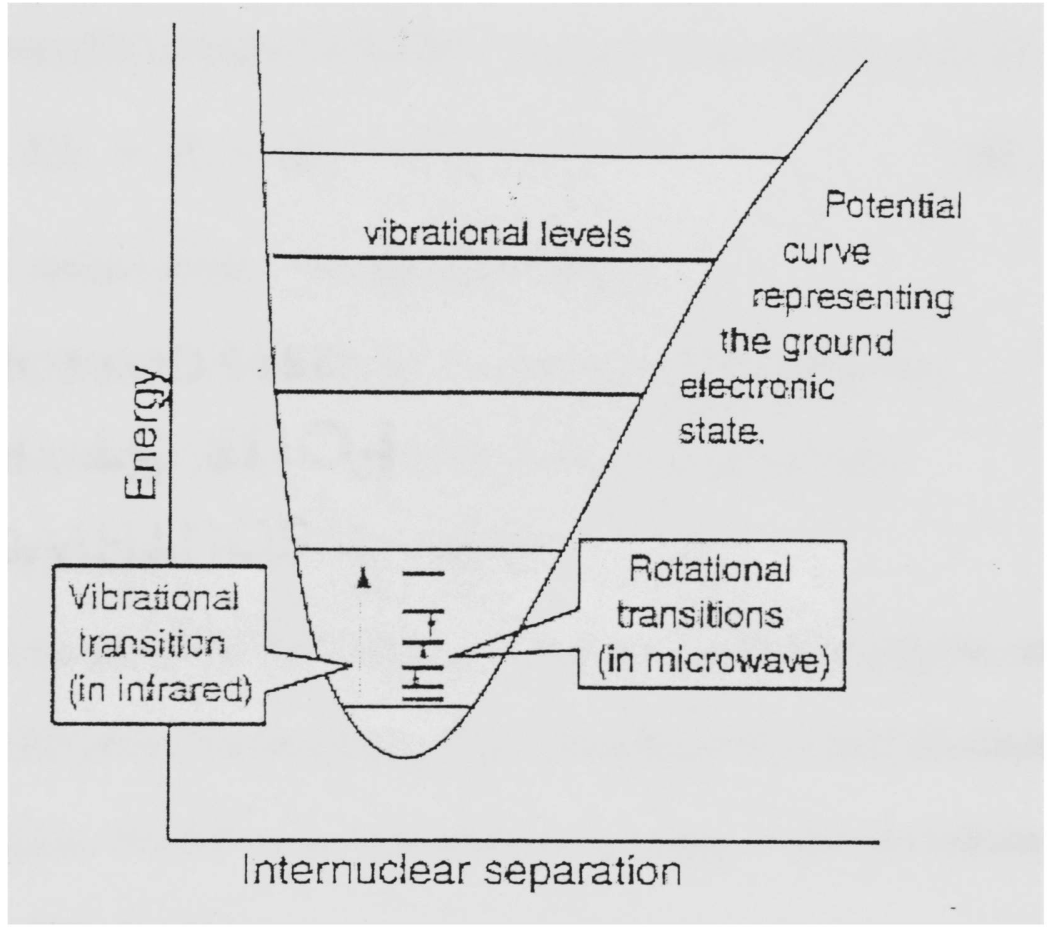

Figure 2

Schematic representation of the vibrational and rotational levels in a molecule. 


\section{III.4 FINAL ATOMIC PRODUCT STATES IDENTIFICATION}

The DR products of $\mathrm{He}_{2}^{+}$are a ground state helium atom and an excited helium atom (see III.1.1). The helium excited atom, $\mathrm{He}^{*}$ can be in any energy level lower than that of the ion, including the ground state.

The kinetic energy $(\mathrm{KE})$ released in the $\mathrm{DR}$ reaction is given by $[14,15,16,17]$ :

$$
K E=E_{i}-D_{m}-E_{f s}+E_{e}
$$

where: $E_{\mathrm{i}}$ is the ionization energy of the helium atom;

$D_{m}$ is the dissociative energy for the ground state molecular ion;

$\mathrm{E}_{\mathrm{fs}}$ is the energy of the excited atom product of DR reaction;

$E_{e}$ is the energy if the incident electron.

In this equation the energy of the incident electron is considered negligible, and the kinetic energy, KE released in the reaction is considered to be evenly distributed between the atomic products. The $\mathrm{KE}$ is the sum of kinetic energies of the two helium atoms, produced by the DR reaction:

$$
K E=m \cdot V_{D R}^{2}
$$

If the $\mathrm{DR}$ reaction occurs from an excited vibrational and rotational state of the molecule, then $D_{m}$ in equation (III.4.1) is replaced by:

$$
D_{m e}=D_{m}-G(v)-F(J)
$$


Using the expressions (III.3.8b) and (III.3.14) for $G(v)$ and $F(J)$ in which only the linear and quadratic terms are retained, the dissociative energy for the rovibrational excited molecule can be calculated.

$$
\begin{gathered}
G(v)=\omega_{e}(v+1 / 2)-\omega_{e} x_{e}(v+1 / 2)^{2} \\
F(J)=B_{v}(J(J+1))-D_{v}(J(J+1))^{2} \\
B_{v}=B_{e}-\alpha_{e}(v+1 / 2) \\
D_{v}=D_{e}+\beta_{e}(v+1 / 2)
\end{gathered}
$$

where: $G(v)$ is the vibrational energy and $F(J)$ is the rotational energy in $\mathrm{cm}^{-1}$ units;

$$
\begin{aligned}
& \omega_{\mathrm{e}}=\text { vibrational spacing, } \\
& \omega_{\mathrm{e}} \mathrm{X}_{\mathrm{e}}=\text { the anharmonicity constant } \\
& \mathrm{B}_{\mathrm{e}}, \mathrm{D}_{\mathrm{e}}=\text { the rotational constant for the hypothetical vibrationless }
\end{aligned}
$$
condition.

$$
\alpha_{e}, \beta_{\mathrm{e}}=\text { the rotation vibration interaction parameters. }
$$

By replacing the expressions for vibrational and rotational energies (III.4.4a,b) and (III.4.5a,b) in equation (III.4.3) we get the value $\mathrm{D}_{\mathrm{me}}$ for the dissociation energy of the vibrational and rotational excited molecular ion.

Using different pairs of vibrational and rotational numbers $(\mathrm{v}, \mathrm{J})$ and different values for the energy of the excited $\mathrm{He}$ atom product of $\mathrm{DR}, \mathrm{E}_{\mathrm{fs}}$, the possible values for the velocities of the atomic products are calculated. 


\section{III.5 MULTICHANNEL QUANTUM DEFECT THEORY (MCQDT) DESCRIPTION OF DR}

The discussion below follows those given in $[10,18,19,20,21,22,23,24]$

The DR of diatomic molecular ion can be viewed as a collision and this process may be regarded as a system consisting of a molecular ion core and an incoming electron, which interact over a range of distances. At large distances, when the distance between the electron and the molecular ion is much larger than the distance between the two atoms of the molecule, the interaction between the electron and the molecular ion can be adequately described by a Coulombic potential. At small distances (comparable with the distance between the two atoms of the molecule) the electron and the molecular ion form a complex through which both energy and angular momentum can be exchanged and dissociation into two neutral atoms may occur [10].

From the point of view of collisions, the word 'channel' indicates a set of states consisting of an incoming electron of arbitrary energy and of a target ion in given stable electronic state (generally the ground state) and in different vibrational and rotational levels. For simplicity, in theoretical calculations the molecular rotation is neglected. The orbital angular momentum of the incoming electron couple with the angular momenta of the molecular ion and yield a state with well defined total angular momentum component with respect to the internuclear axis [10].

As the electron penetrates the reaction zone, the incident electron and the molecular ion form an excited molecular complex as a whole and many body interactions prevail, such as electron-electron correlations and interactions between various internal degrees of 
freedom (eg. vibronic). The excited states of the diatomic molecule may be classified as Rydberg states and non-Rydberg states. Rydberg series usually converge to various ionization thresholds corresponding to various states of the molecular ion.

Such an 'electron+molecular ion' system is characterized by various combinations of the orbital energy of the electron and the ion in a specified energy level, specifying the angular momentum of the electron and the ion and their coupling. Such a combination identifies one possible mode of dissociation of the system, and is called a dissociation channel [18].

The short lived molecular dissociative states in which the 'electron+molecular ion' system is converted may fragment in two atoms, a process summarized by the following reaction scheme:

$$
H e_{2}^{+}(J, v)+e^{-} \rightarrow\left\{H e_{2}^{*}, H e_{2}^{* *}\right\} \rightarrow H e+H e^{*}
$$

where $\mathrm{J}$ and $\mathrm{v}$ denote, respectively, the initial rotational and vibrational level of the groun-state molecular ion. The electron may be captured directly into a dissociative state (doubly excited), or can be first captured into a bound Rydberg state $\mathrm{He}_{2}{ }^{*}$ which is predissociated by electronic interaction with the dissociative state $\mathrm{He}_{2}{ }^{* *}$. The dissociation of the excited molecule can take place along several dissociation paths.

A competitive process has to be considered: the autoionization of the intermediate Rydberg or double excited state of the neutral molecule which can fragment back into 
an electron and a molecular ion in the $\left(\mathrm{J}^{\prime}, \mathrm{v}^{\prime}\right)$, usually different from the initial $(\mathrm{J}, \mathrm{v})$ rovibrational state of the molecular ion.

$$
H e_{2}^{+}(J, v)+e^{-} \rightarrow\left\{H e_{2}^{*}, H e_{2}^{* *}\right\} \rightarrow H e_{2}^{+}\left(J^{\prime}, v^{\prime}\right)+e^{-}
$$

A simultaneous description of these different processes, namely 'direct' , 'indirect' DR and autoionization of the intermediate Rydberg state $\mathrm{He}_{2}{ }^{*}$

or doubly excited $\mathrm{He}_{2}{ }^{* *}$ neutral molecule, is conveniently handled within the multichannel quantum defect theory (MCQDT), extended to the molecular case with dissociative channels in addition to the usual ionization channels [10].

Dissociative states correspond to open channels (open for fragmentation in two atoms). An ionization channel may be open or closed depending on whether the total energy (ion plus electron) lies above or below its ionization threshold, defined by a given $(\mathrm{J}, \mathrm{v})$ level of the ground state molecular ion. The molecular complex may break either into the electron and the molecular ion, or into two neutral atoms according to various dissociation channels.

The central feature of Quantum Defect Theory (QDT) is that it relates the structure of highly excited atoms or molecules to their decay, or chemical transformaion: ionization and dissociation. A complete theory of diatomic molecules should be indistinguishable from a complete theory of atom-atom scattering. The total Hamiltonian of a molecule $\mathrm{AB}$ is identical to the total Hamiltonian for the collision of atom $\mathrm{A}$ and atom $\mathrm{B}$, and the eigenfunctions we obtain should be equivalent. The only difference is the emphasis one puts on certain classes of solutions, defined by their asymptotic boundary conditions. 
However, if we include asymptotically decaying closed channels in atomic scattering theory, we should obtain the bound states of the molecules and, if we include the continuum states in the molecular theory, we should obtain the proper scattering wave functions [24]. By extending methods of scattering theory into bound states regions, QDT thus establishes a connection between properties of matter which are often conceived as being fundamentally different.

QDT derives its name from the empirical parameter $\mu$ contained in the Rydberg formula for the levels of a regular series[20].

$$
E_{i}=I-\frac{R y}{\left[n_{i}-\mu(R)\right]^{2}}
$$

where: I= ionization energy

$$
\begin{aligned}
& \mathrm{Ry}=\mathrm{Rydberg} \text { constant } \\
& \mathrm{n}_{\mathrm{i}}=\text { the principal quantum number }
\end{aligned}
$$

The quantum defect function which characterize the non Coulomb parts of the potential resulting from the interaction of a Rydberg electron with the core may be expanded in a Taylor series:

$\mu(R)=\mu\left(R_{e}^{+}\right)+\frac{d \mu}{d R}\left(R-R_{e}^{+}\right)+\ldots$

where: $R_{e}^{+}$is the equilibrium internuclear distance of the ion core. 
The constant term in the expansion is independent of the nuclear motion and result in part from the penetration of the core by the Rydberg electron, as in the atomic case. In a molecule, the separation of the nuclei produces another departure from a pure Coulombic field and results in a contribution to the quantum defect which depends on the core splitting.

The central idea is to treat a series of levels as a whole representing all the level positions, line intensities and the other spectral properties in terms of a small set of parameters [21]. This procedure is made possible by the fact that most obvious spectral properties depend primarily upon the radial motion of an excited electron outside the core, i.e in the region where it experiences only the Coulomb field. On the other hand, any perturbations of the complicated short range electron-core interaction acts only by shifting all the levels and their intensities according to simple relationships.

Therefore, the QDT deals with an entire unperturbed Rydberg series, plus its adjacent continuum at one time, which together constitute a channel. The key idea is to study a many-electron system when it is separated into a core and an escaping electron. Under these circumstances the analytical expression of the total wave function is greatly simplified, being the product of a core function times the wave function of an excited electron in a Coulomb field. All of the effects of short range interactions are represented by adding to the regular solution $\mathrm{f}$ of the electronic radial motion in the Coulomb field a irregular one $\mathrm{g}$, with the same energy $\in$ in the form:

$f(\varepsilon, r) \cos \pi \mu(\varepsilon)-g(\varepsilon, r) \sin \pi \mu(\varepsilon)$ 
The coefficients of this linear combination are trigonometric functions of a phase shift $\pi \mu(\varepsilon)$ resulting from the form of the short-range interactions.

The main generalization of QDT is due to Seaton [22], who introduced alternative channels, i.e. alternative modes of excitation (hence the name of MQDT) extending the close coupling formulation of scattering theory to the range of negative energies.

An interesting situation arises when a molecule is excited to energies where both disscociation and ionization are energetically possible so that a competition between predissociation and preionization occurs [23]. The passage of a molecular system from a closed channel, i.e. a discrete (usually Rydberg) level, into an open electronic or nuclear channel (ionization or dissociation continuum) is mediated by interactions between particles at short range, where the fragments form the molecular complex. 


\section{III.6 CROSS SECTION FOR THE DR REACTION CALCULATED BY MCQDT}

In [10] the cross section for the $\mathrm{DR}$ reaction of the $\mathrm{He}_{2}{ }^{+}$is calculated using the Multichannel Quantum Defect Theory (MCQDT) applied to molecular case, with ionization and dissociation channels simultaneously included. The calculations presented in [10] are intended to help in the understanding and measurement of the DR process of $\mathrm{He}_{2}{ }^{+}$with slow electrons $(0.1 \mathrm{meV}-2.0 \mathrm{eV})$.

The MCQDT treatment of DR requires data for the molecular ion curves and the relevant dissociative curves of the neutral molecule. In Figure 3 are shown the curves that were considered to have relevance for the DR process (III.5.2) with slow electrons. The tick lines correspond to ion states calculated by Sunil et al [28] (the attractive curve correspond to the $\mathrm{X}^{2} \Sigma_{u}^{+}$ion ground state and the repulsive curve is the first excited state $\mathrm{A}^{2} \Sigma_{g}^{+}$). The thin attractive continuous lines represent Rydberg states with $\mathrm{n}=3$ and $\mathrm{n}=4$.

The dashed line is a dissociative state with ${ }^{1} \Sigma_{g}^{+}$symmetry. The dotted line is a dissociative state with ${ }^{3} \Pi_{u}$ symmetry and the continuous thin line is the lowest dissociative state. The three dissociative curves are Rydberg states of $\mathrm{He}_{2}$ with the repulsive state $\mathrm{A}^{2} \Sigma_{g}^{+}$as ionic core. 
The calculations were done for three isotopomers built from the two isotopes ${ }^{3} \mathrm{He}$ and ${ }^{4} \mathrm{He}:{ }^{3} \mathrm{He}_{2}{ }^{+},{ }^{4} \mathrm{He}_{2}{ }^{+}$and the mixed variety ${ }^{3} \mathrm{He}^{4} \mathrm{He}^{+}$. The heteronuclear ion has a small permanent molecular dipole which permits a more rapid relaxation of vibrationally excited molecular ions. This feature is important for obtaining a predominantly populated a ground vibrational level. A known distribution of the vibrational levels makes the comparison of the experimental result with the theory much easier. $\mathrm{For} \mathrm{He}_{2}{ }^{+}$ this advantage can be canceled by the very small DR cross section of ions initially in the ground state, which can make it difficult to measure. Although most of the results are shown for the mixed isotope ${ }^{3} \mathrm{He}^{4} \mathrm{He}^{+}$, the qualitative arguments stand for all the three isotopomers.

The features of the DR cross section for the direct process only, for $(J=0, v=0)$ and $(\mathrm{J}=0, \mathrm{v}=4)$ initial vibrational levels of the molecular ion for all dissociative paths are shown in Figure 4. Each step down seen in the cross sections coincides with the inclusion of a new open channel, i.e., to the threshold for further autoionization competing with DR. In Figure 5 the total cross section of DR is given as the sum of the partial cross sections along each route, for initial rovibrational level $(v=0, J=0)$, in a smaller range of energies. In Figure 6 is shown the effect of the initial vibrational excitation. 


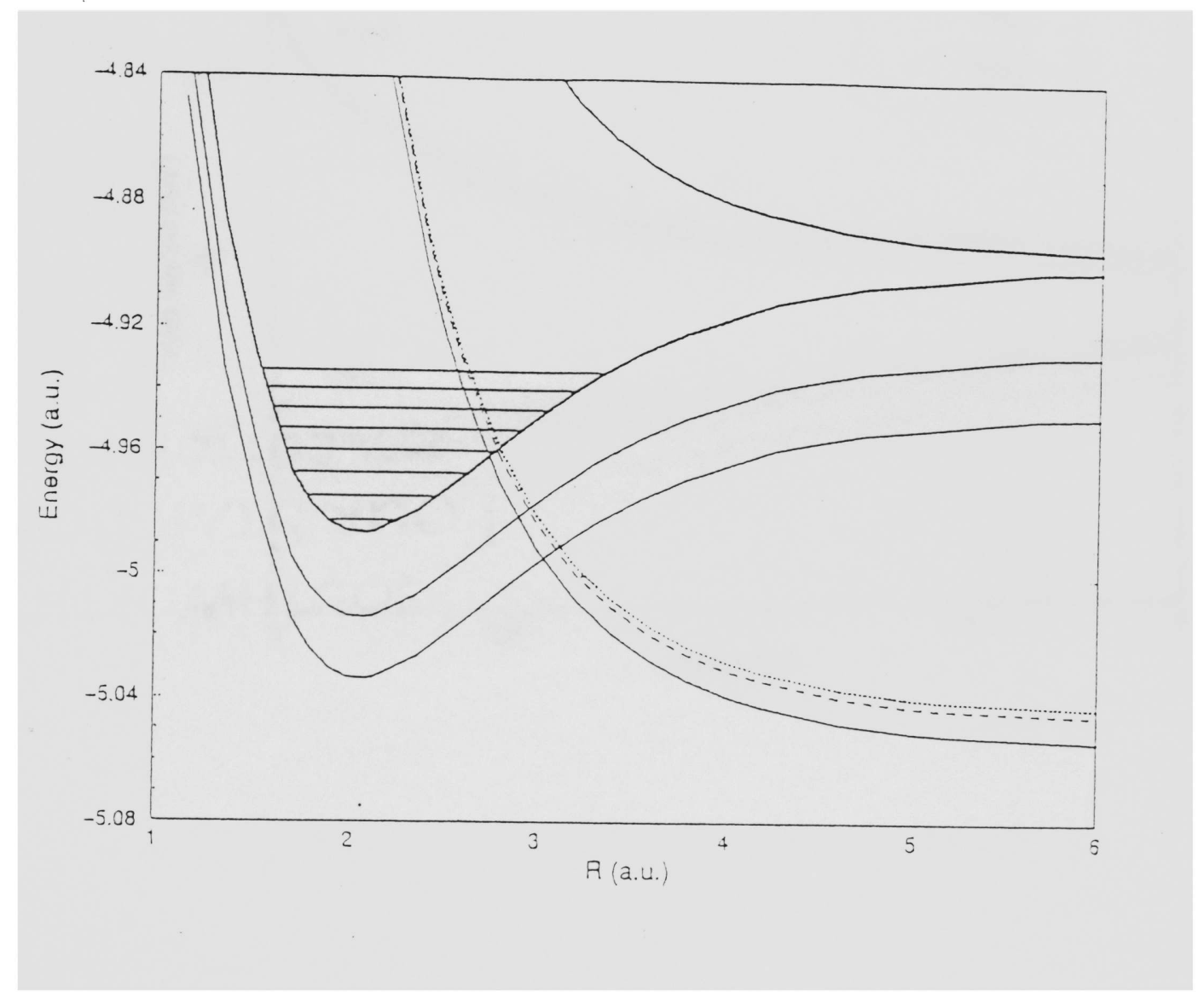

Figure 3

Potential-energy curves involved in DR of $\mathrm{He}_{2}{ }^{+}$with slow electrons[10]. 


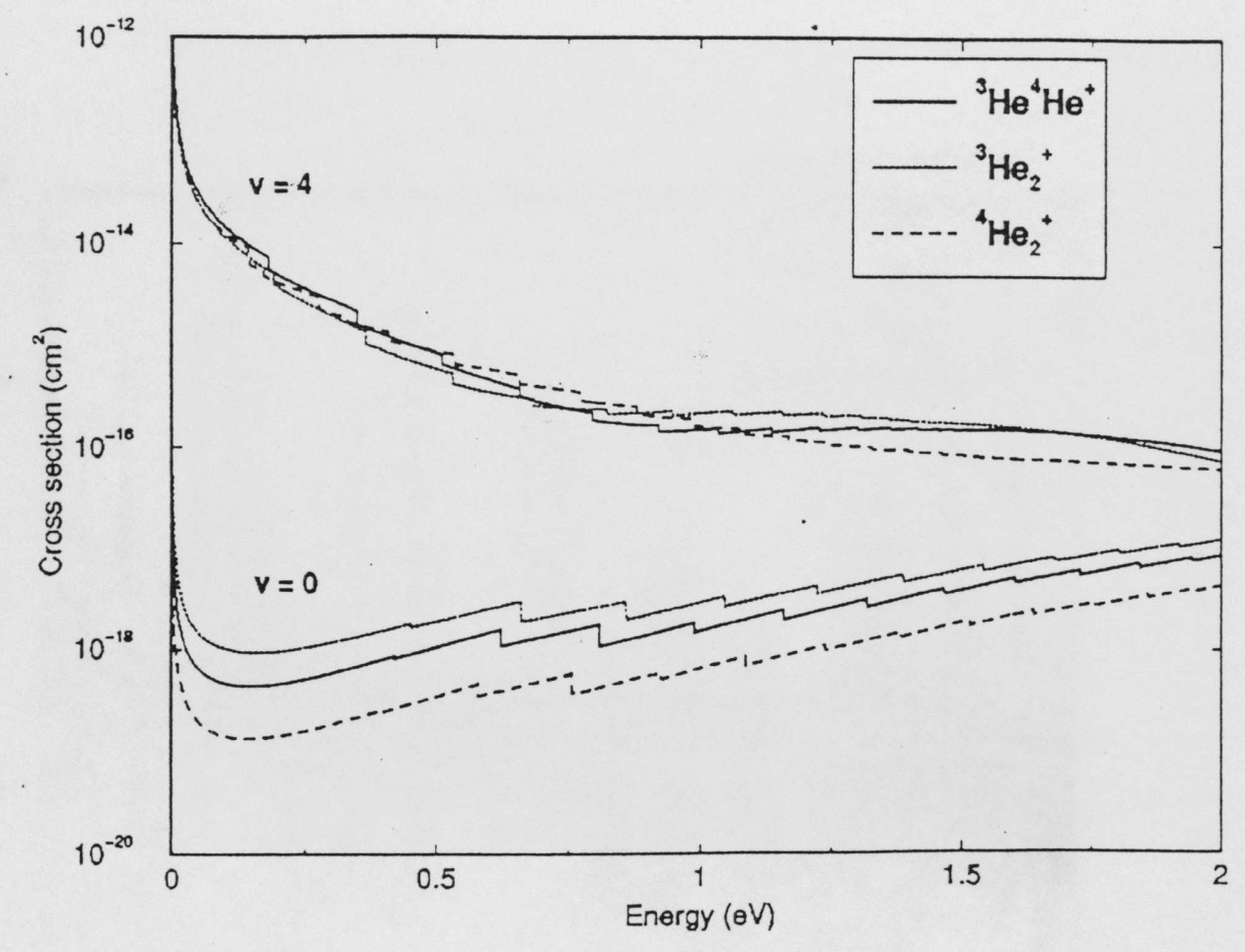

Figure 4

DR cross section (isotopic effect) for the direct process for $\mathrm{v}=0, \mathrm{~J}=0$ and $\mathrm{v}=4, \mathrm{~J}=0$ initial state. Dashed lines represents direct DR cross section for ${ }^{4} \mathrm{He}_{2}{ }^{+}[10]$. 


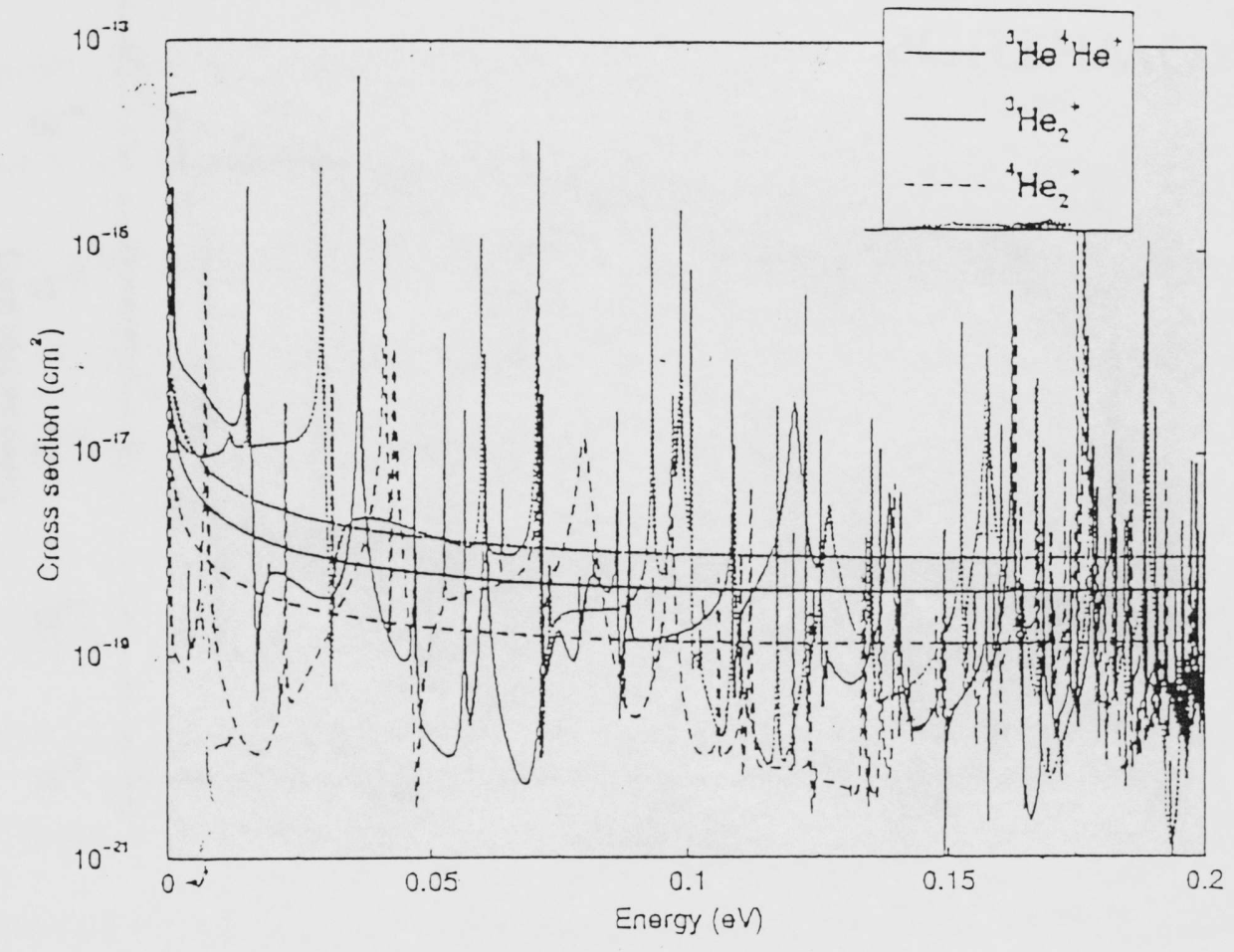

Figure 5

Same as figure 4 for the global (direct plus indirect) process, starting from $v=0 \mathrm{~J}=0$ initial level in a smaller range of energies (0-0.2) eV [10]. 


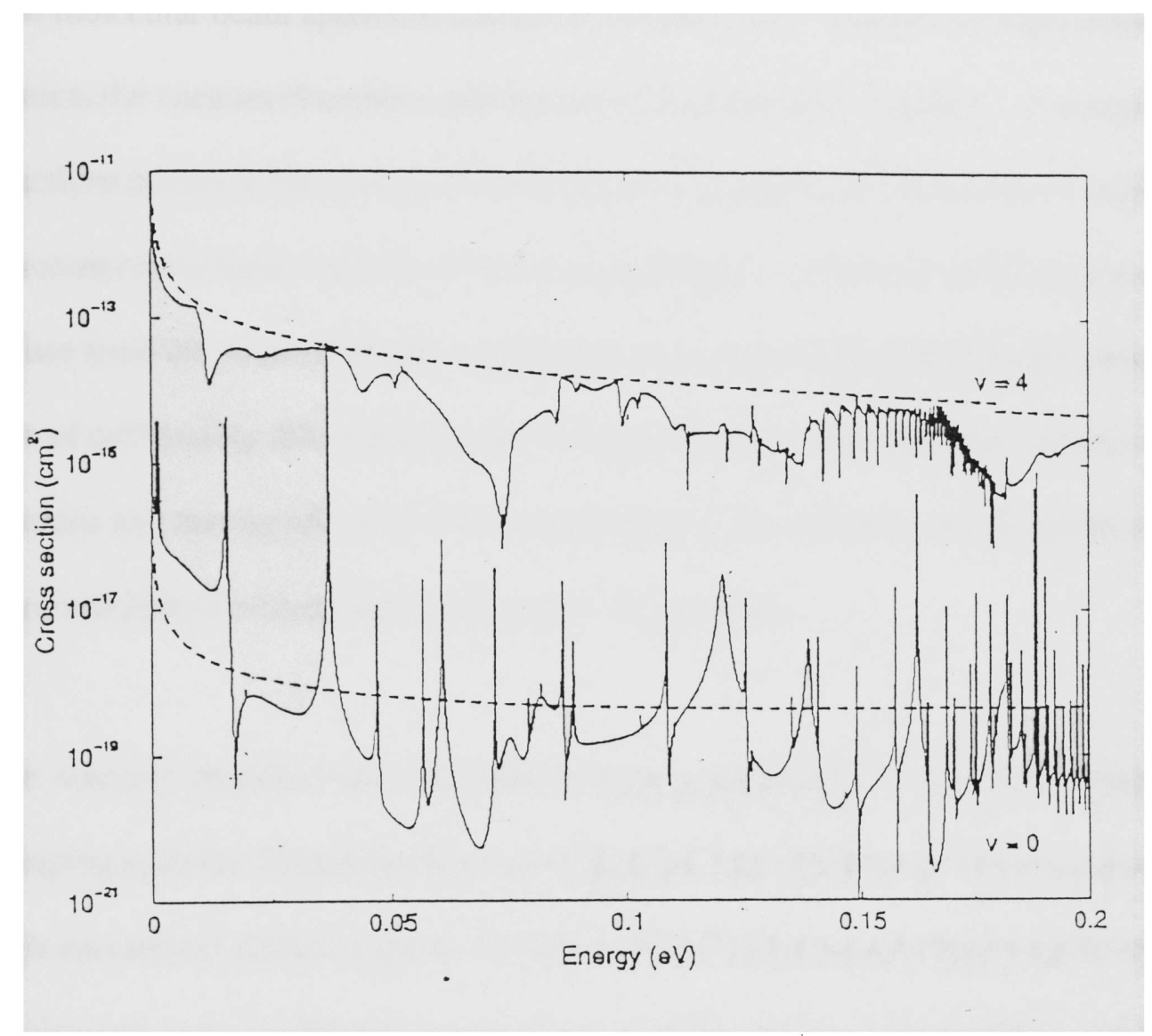

Figure 6

Effect of the initial vibrational excitation.

Total DR cross section (summed over the three lowest Dissociative states for $\mathrm{v}=0$ and $\mathrm{v}=4$ initial vibrational levels $(\mathrm{J}=0)$ of the molecular ion . Dashed lines: direct process only; full lines; direct plus indirect process [10]. 


\section{APPARATUS}

The molecular beam apparatus used in the present work consists of three sections: the source, the vacuum chambers and the detector as shown in Figure 7. A complex set of reactions occurs in the source: electron impact ionization, electron impact excitation, associative ionization and dissociative recombination. The products of these reactions effuse from the source through a small exit slit and go toward the detector passing three sets of collimating slits placed in the vacuum chambers. The detector is sensitive only to photons and metastable atoms. The ionized atoms, the electrons and Rydberg states are removed from the beam before they reach the detector.

The vacuum chambers are evacuated to approximately $10^{-7}$ torr by three independent pumping systems. Each pumping station consists of a mechanical foreline pump and a high vacuum oil diffusion pump. In [26] details are given about the pumping speed of the mechanical and oil diffusion pumps along with the values of the roughing and foreline pressures. The three oil diffusion pumps have sufficient pumping capacity to maintain the pressure in the three chambers at a value of about $10^{-7}$ torr. The three chambers can be isolated from each other and from the diffusion pumps with the aid of isolation valves and pneumatic gates. The isolation system helps to conserve the high vacuum in case of accidental power loss. The vacuum is monitored by thermocuple gauges for the forelines and ionization gauges for the high vacuum chambers. 
The source (Figure 8) consists of a Pyrex tube approximately $3.1 \mathrm{~cm}$ in diameter and 10 $\mathrm{cm}$ long. The Pyrex tube is mounted on a source flange. The cathode of the source is a tungsten filament mounted on the source flange. The active part of the filament is coated with thorium to increase the number of electrons produced by filament. At the opposite end of the Pyrex tube there is an aluminium anode with a $9.5 \times 0.2 \mathrm{~mm}$ exit slit.

Helium gas flows in the source at constant pressure, controlled by an automatic pressure controller (Grandville-Philips, model 216 ). The pressure in the discharge is kept in the range 3-30 mTorr by an automatic pressure controller which uses a reference voltage to open or close the valve to maintain the desired pressure range.

A potential difference of approximately $400 \mathrm{~V}$ is applied between the cathode and the anode to initiate the discharge. The discharge is sustained by a $200 \mathrm{~V}$ potential across the source. The plasma created in the source consists of photons, electrons, excited atoms, ions, Rydberg state atoms and molecules.

The mixture of particles effuses through the exit slit and travels toward the detector.

Outside the exit slit is a beam chopper. The chopper is an alumininum wheel of $7.8 \mathrm{~cm}$ in diameter. The wheel can have 1,2 or 4 slits and is driven by a motor at a frequency of $60 \mathrm{~Hz}$. The chopper is the key of the Time of Flight Analysis and is discussed later. The chopped beam passes a total of three collimating slits, the last one being placed in front of the detector. 
A pair of sweep plates providing a field of $500 \mathrm{~V} / \mathrm{cm}$ are used to deflect ions, electrons and to remove possible Rydberg states atoms from the beam. After passing the sweep plates the beam consists only of photons, metastable and neutral atoms.

The beam apparatus is equipped with two Channeltron Electron Multiplier (CEM) detectors (Figure 9) mounted on a support and placed perpendicular to the beam. First detector is placed at a distance of $0.533 \mathrm{~m}$ from the chopper. The second detector is placed at a distance of $1.778 \mathrm{~m}$ from the chopper, in the third chamber. Each detector system consists of $5 \times 0.05 \mathrm{~mm}$ slit and a Channeltron Electron Multiplier (CEM) detector. The detectors are sensitive to photons and metastable atoms. The metastable atom colliding with the detector causes the ejection of one electron through Auger effect. The electron is accelerated through a difference potential and multiplied in a cascading process. This cascading process ends when an electron cloud of about $10^{8}$ electrons is collected at the anode creating a single pulse. An electronic system consisting of a preamplifier, an amplifier, and a single channel analyzer shapes the pulse, amplifies it and the pulse is finally recorded with a ORTEC multichannel scaler card and software according to the time it was produced. 


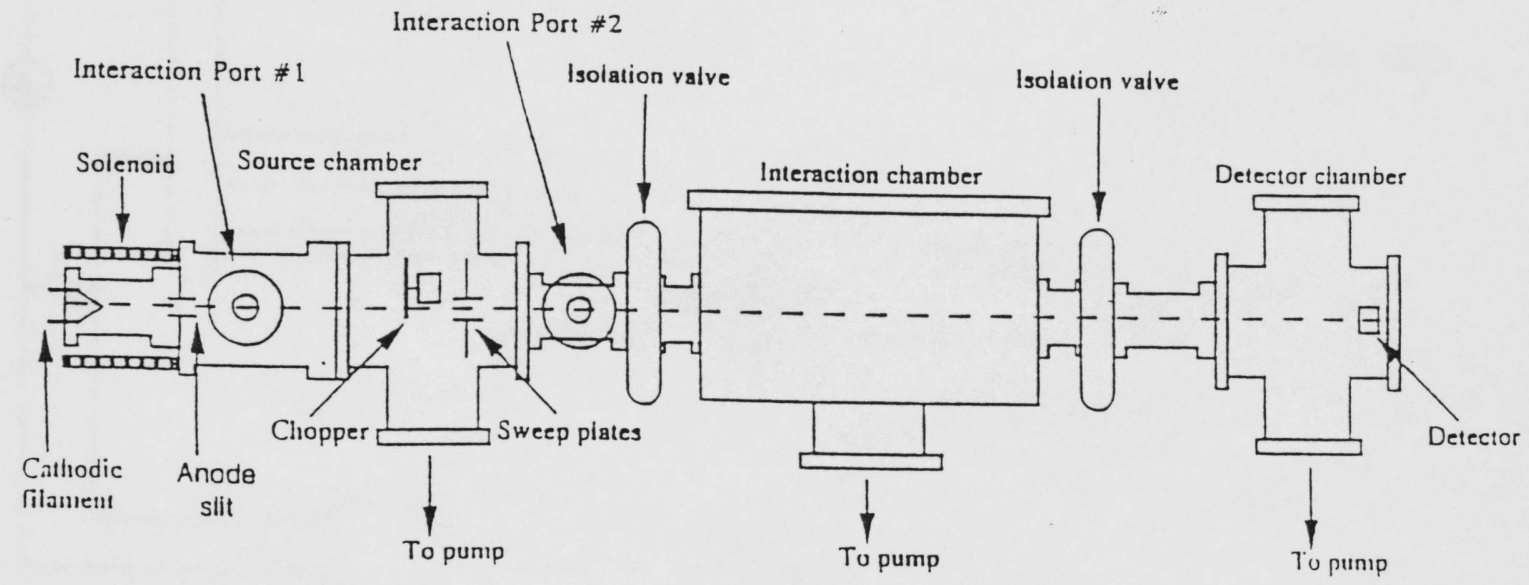

Figure 7

The molecular beam apparatus. For this thesis the molecular beam apparatus has been equipped with an additional detection system placed at $0.533 \mathrm{~m}$ from the chopper. 


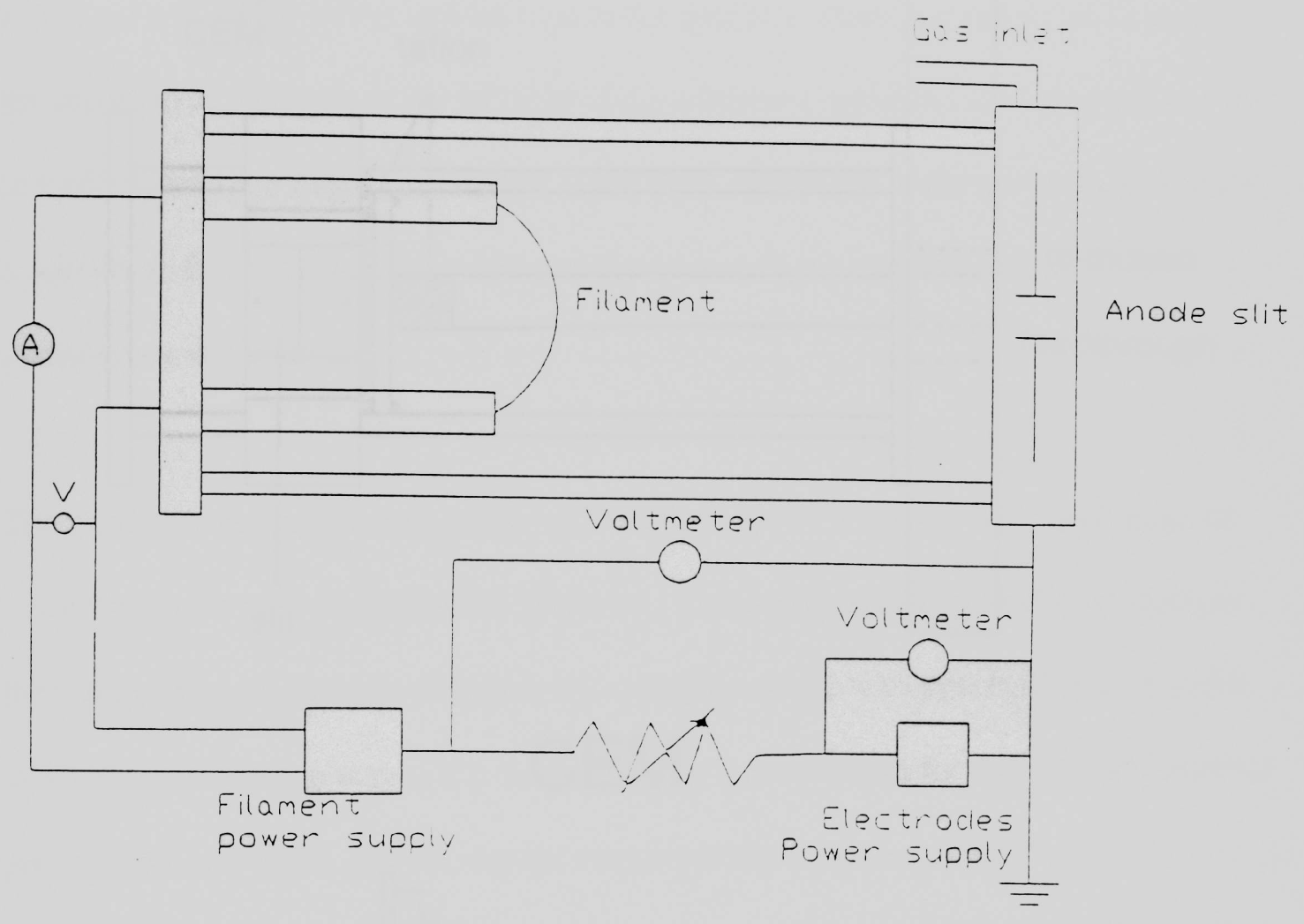

Figure 8

The metastable atom source glow discharge tube with a block diagram for the electronics. 


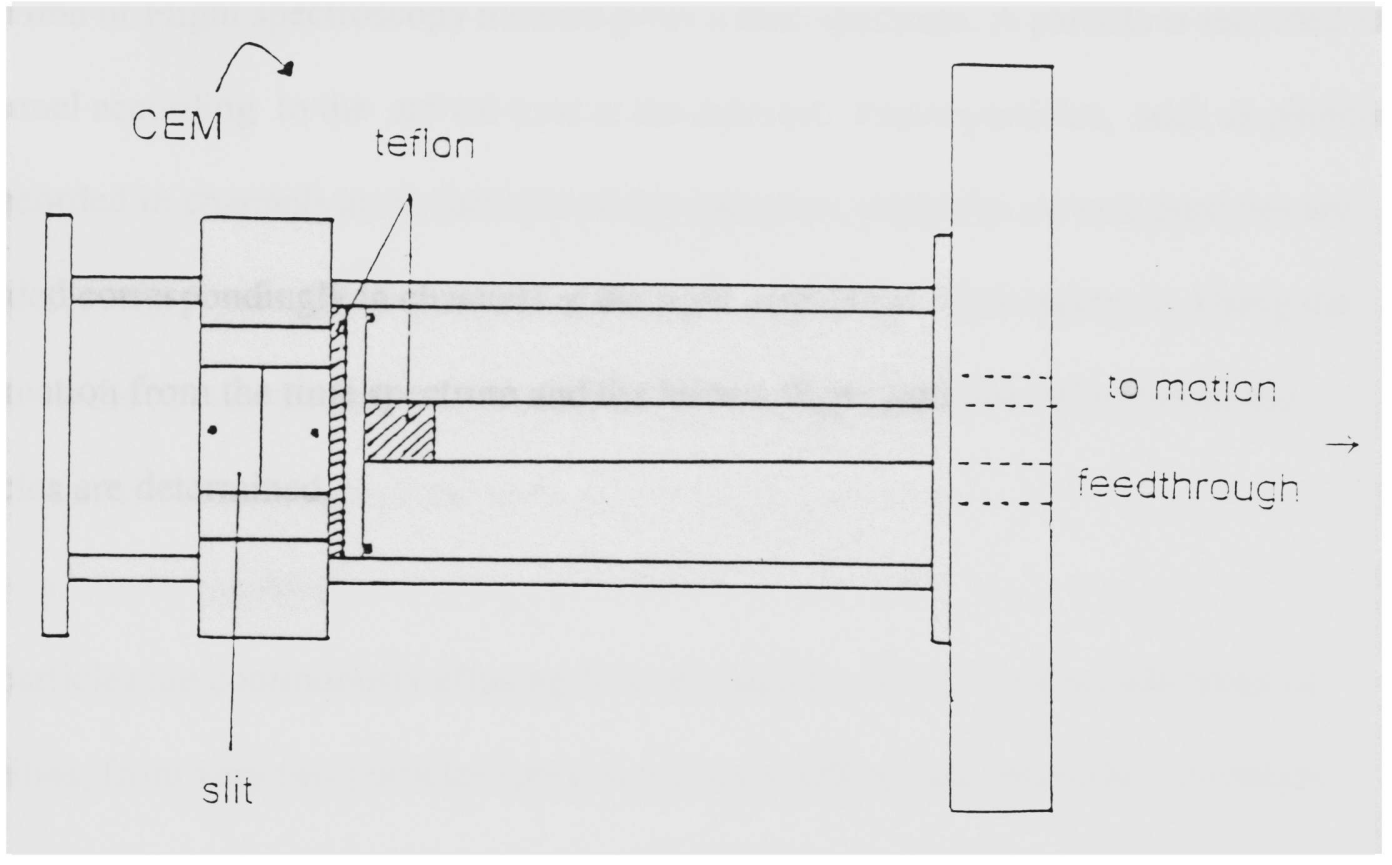

\section{CEM}

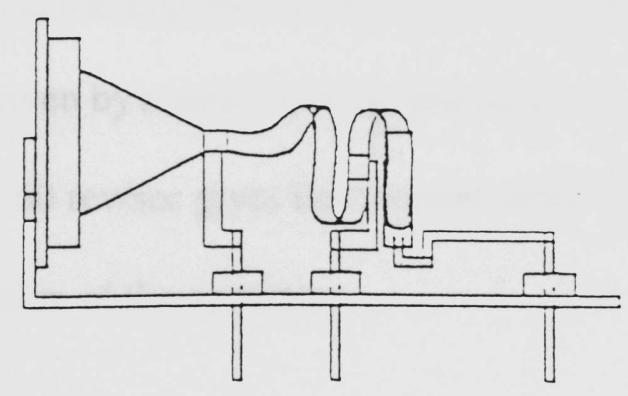

Figure 9

The channel Electron Multiplier (detector) [27] 


\section{TIME OF FLIGHT ANALYSIS}

The Time of Flight spectroscopy method gives a time spectrum. A particle is recorded in a channel according to the arrival time at the detector. Faster particles, such as photons, are recorded in channels at the left side of the spectrum, while the slowest particles are recorded correspondingly in channels at the right end of the time spectrum. Using the information from the time spectrum and the known flight path, the velocities of the particles are determined.

The particles are continuously effusing from the source. They cover a wide range of velocities, from very fast particles (photons) to slow DR atomic products. To analyze these velocities the beam is chopped by a chopper wheel with slits $0.75 \mathrm{~mm}$ in width. When the slit is in the way of the beam, particles pass through for a short time interval given by the slit width and the angular velocity of the chopper wheel.

The chopper wheel is driven by a small synchrotonous motor at a frequency of $60 \mathrm{~Hz}$. This angular velocity of $60 \mathrm{rev} / \mathrm{sec}$ gives the chopper wheel slit an open time of $80 \mu \mathrm{s}$, which is the time resolution of the apparatus.

The TOF spectra of the metastable atoms are recorded in channels $40 \mu \mathrm{sec}$ wide. In our experiment we used different chopper wheels, with 1,2 and 4 slits.

The sweep lengths are respectively 416, 208, 104 channels. The velocity resolution of the TOF method is only limited by the chopper open time. 
For $\Delta \mathrm{t}_{\mathrm{c}}=80 \mu \mathrm{sec}, \Delta \mathrm{v}=4^{*} \mathrm{v} /$ (channel-photon peak). For the velocity $400 \mathrm{~m} / \mathrm{s}$, the resolution is $20 \mathrm{~m} / \mathrm{s}$. As the atom's velocity decreases, the resolution of the method is better.

The electronic system for time of flight analysis is shown in Figure 10. When the chopper is open, the light from the light-emitting diode (LED) stimulates the photo-transistor. The LED and the photo-transistor are located at opposite sides of the chopper wheel, such that the photo-transistor is stimulated only when the chopper is open. The signal generated by the transistor is amplified and delayed in order to ensure coincidence with photoelectron pulses from the ultraviolet (UV) photons which travel down the beam path when the chopper opens. This signal is used as a reference or start signal for the time analyzer. At the end of the flight path, photons and atoms are detected by measuring electrons ejected from the detector cone by either the photoelectric effect or Auger effect. The beam path length guarantees sufficient TOF for all excited atoms to undergo optical decay before reaching the detector, except for metastable atoms. 


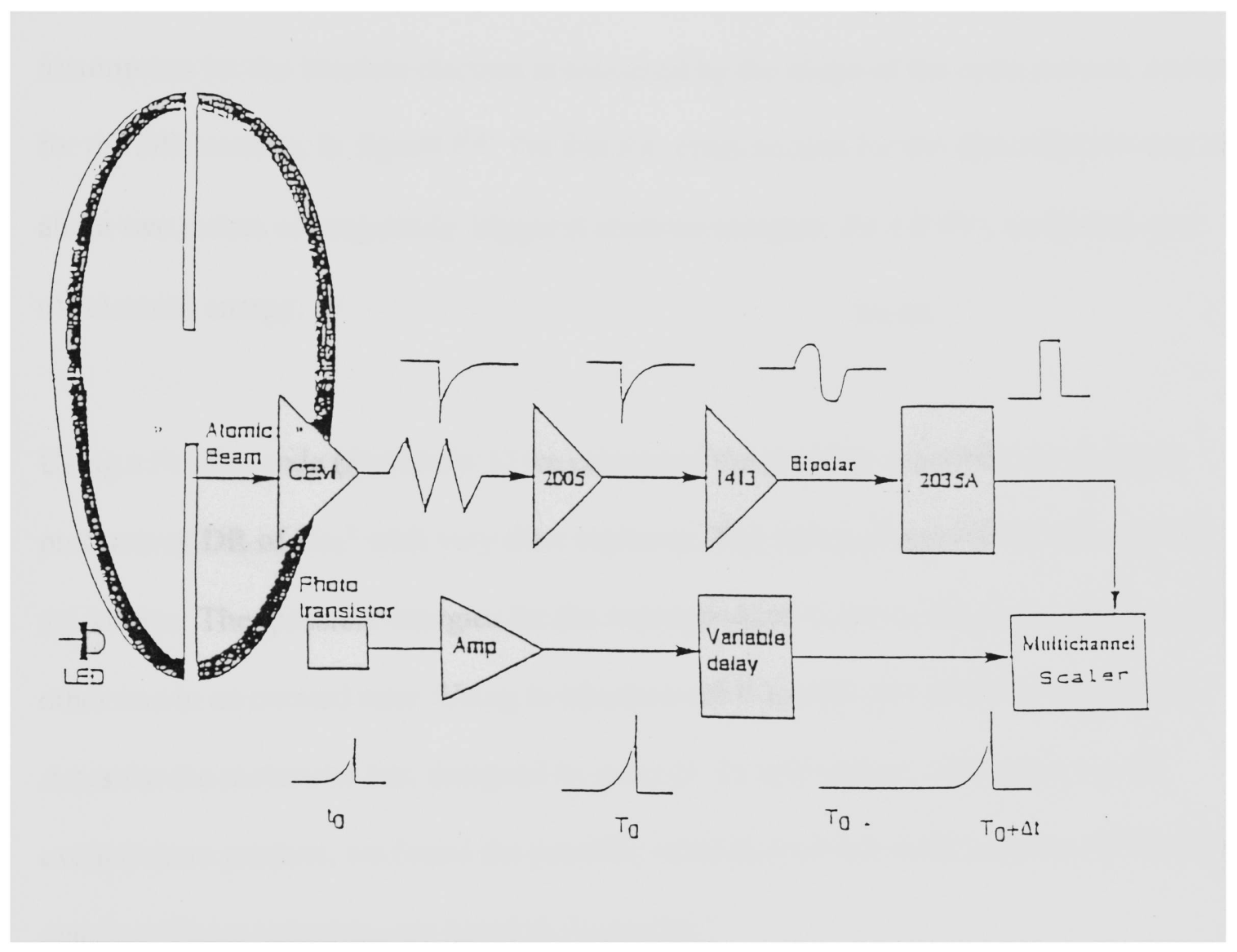

Figure 10

Electronic System for Time-Of-Flight Analysis 


\section{DATA INTERPRETATION}

In the analysis of the experimental results we have some assumptions. First, in equation (III.4.1) we considered the energy of the incident electron negligible. The zero energy assumption for the incident electron is sustained by the shape of the cross section curve for the $\mathrm{DR}$ reaction. In figure 4 shows that the cross section for the direct DR process is about two orders of magnitude bigger at electron energies $\mathrm{Ee} \cong 0 \mathrm{eV}$, compared to 1 eV electron energy.

Using a Fortran code (Appendix 1) we calculated the possible velocities for the atom products of $\mathrm{DR}$ of $\mathrm{He}_{2}{ }^{+}$with very slow electrons. The energy levels in the helium atom are known. The possible energies for the atom products is one in the ground state and the other one in an excited state. Using in equation (III.4.1) different initial rovibrational states for the molecular ion, designed by pairs $(\mathrm{v}, \mathrm{J})$, and various final states for the excited atom product, we found the possible velocities for the atom products of the DR reaction. These velocities are listed in Appendix 2.

Equation (III.4.1) also allows both product atoms in ground state. In this case they will have very high velocities, depending on the rovibrational state of the molecular ion. However, the curve crossing model for DR [9] do not predict this path of dissociation because there is no intersection between the potential curve of the bound states of helium molecular ion and this particular dissociative curve. The probability of tunneling effect between the two curves is very small. Our experimental results indicate that very high 
velocity product atoms occur in the DR reaction. In Figure 12, the arrow indicates a peak in channel 5 , with a corresponding velocity of about $20,000 \mathrm{~m} / \mathrm{s}$. This peak may be due to DR of helium molecular ion to totally ground state products. The resolution in this region is poor (Figure 11) and it does not allow precise identification of the states of the final atom product. The energy resolution is very good for low energy atoms.

The energy equation (III.4.1) predicts slow atoms with velocities of about $39 \mathrm{~m} / \mathrm{s}$ and $49 \mathrm{~m} / \mathrm{s}$. The second reasonable assumption is that we observe these lines "wrap arounds". The initial flight path of $1.227 \mathrm{~m}$ does not allows us to observe these lines directly since the time of flight $(\approx 1 / 60 \mathrm{~s})$ is too short to allow these slow atoms to reach the detector before the chopper opens again. A simple Fortran code solves these wrap around lines. A $39 \mathrm{~m} / \mathrm{s}$ line is seen as having a velocity of about $80 \mathrm{~m} / \mathrm{s}$, while a $49 \mathrm{~m} / \mathrm{s}$ line is seen as a $150 \mathrm{~m} / \mathrm{s}$ line. In order to verify this wrap around assumption, the molecular beam apparatus has been modified. The flight path has been lengthened to $1.775 \mathrm{~m}$ and a second detector has been placed at $0.533 \mathrm{~m}$ from the chopper. The results obtained using this short flight path proved that our wrap around assumption was correct. We observed also some additional wider lines, which we can explain in terms of resonances in the cross section for the indirect process. 
Energy Resolution (eV)

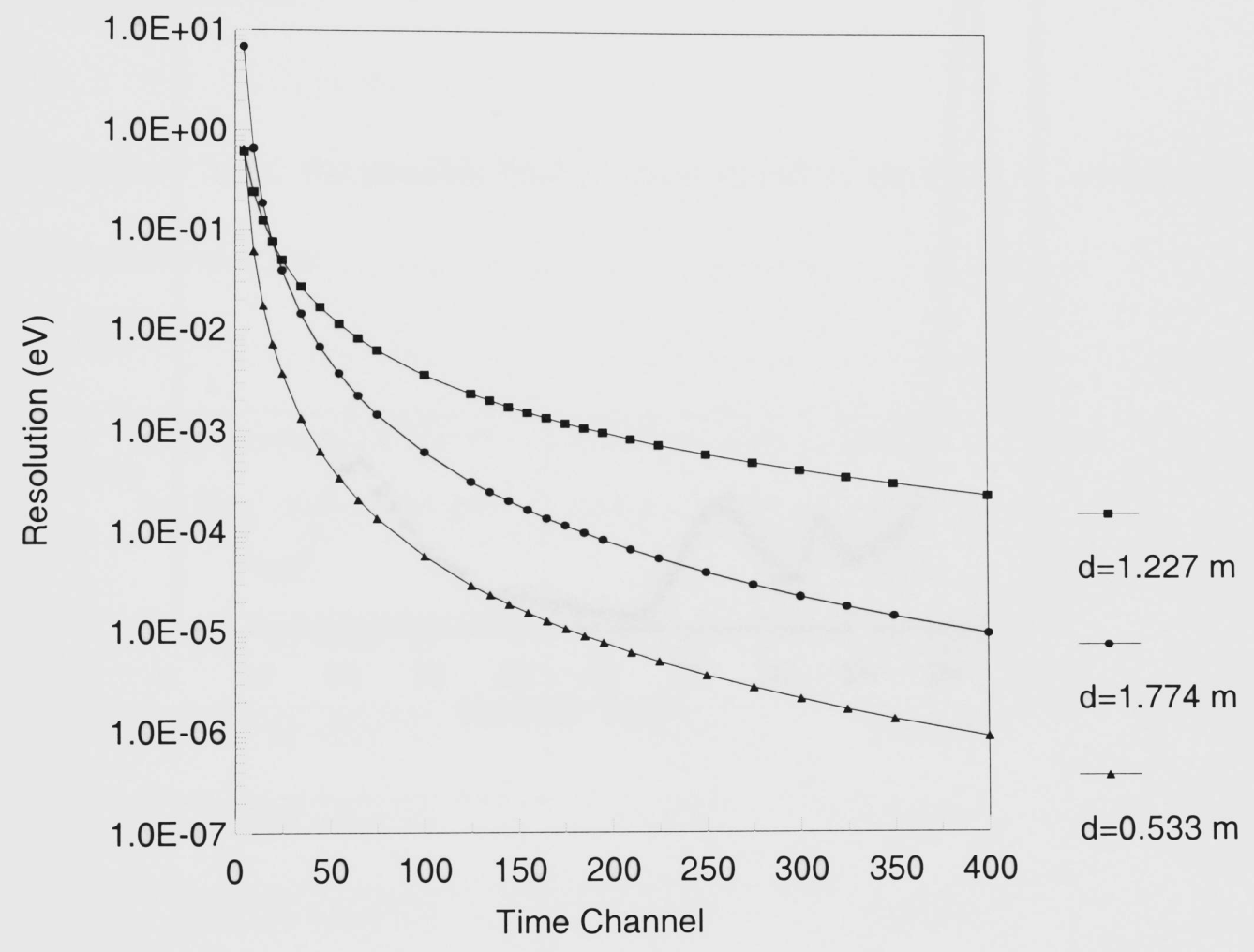

Figure 11

Energy resolution for different lengths of the flight paths. 


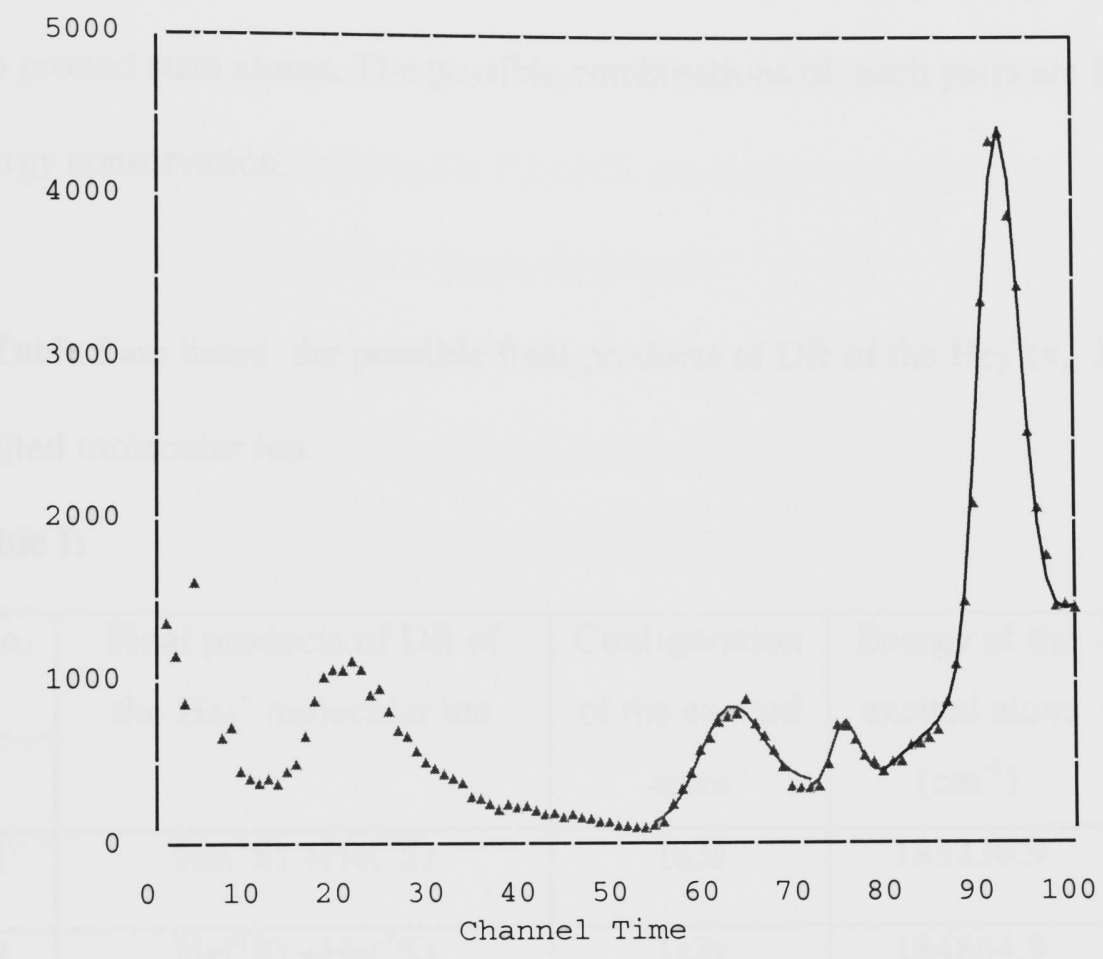

Figure 12

A typical DR spectrum

In the figure above, a total of five DR peaks are shown. The peaks approximately at channel 62,75 and 90 correspond to DR from the $\mathrm{v}=3, \mathrm{~J}=3,2,1$ level of $\mathrm{He}_{2}{ }^{+}$to the $3 \mathrm{~s}^{3} \mathrm{~S}$ level at $183236.08 \mathrm{~cm}^{-1}$ in the He atom. The solid line is a fit to the data. The time channel width is $40 \mu$ s and the flight path is $1.227 \mathrm{~m}$. The photon peak, which is off the scale of the figure, is at channel 5. 
The DR reaction products are pairs of ground state and excited state atom products, or two ground state atoms. The possible combinations of such pairs are limited first, by the energy conservation.

In Table I are listed the possible final products of DR of the $\mathrm{He}_{2}{ }^{+}(\mathrm{v}, \mathrm{J})$ rovibrational excited molecular ion.

\section{Table I:}

\begin{tabular}{|c|c|c|c|}
\hline No. & $\begin{array}{c}\text { Final products of DR of } \\
\text { the } \mathrm{He}_{2}{ }^{+} \text {molecular ion }\end{array}$ & $\begin{array}{c}\text { Configuration } \\
\text { of the excited } \\
\text { atom }\end{array}$ & $\begin{array}{c}\text { Energy of the } \\
\text { excited atom } \\
\left(\mathrm{cm}^{-1}\right)\end{array}$ \\
\hline 1 & $\mathrm{He}\left({ }^{1} \mathrm{~S}\right)+\mathrm{He}\left({ }^{3} \mathrm{~S}\right)$ & $1 \mathrm{~s} 3 \mathrm{~s}$ & 183236.9 \\
\hline 2 & $\mathrm{He}\left({ }^{1} \mathrm{~S}\right)+\mathrm{He}\left({ }^{1} \mathrm{~S}\right)$ & $1 \mathrm{~s} 3 \mathrm{~s}$ & 184864.9 \\
\hline 3 & $\mathrm{He}\left({ }^{1} \mathrm{~S}\right)+\mathrm{He}\left({ }^{3} \mathrm{P}\right)$ & $1 \mathrm{~s} 3 \mathrm{p}$ & 185564.6 \\
\hline 4 & $\mathrm{He}\left({ }^{1} \mathrm{~S}\right)+\mathrm{He}\left({ }^{3} \mathrm{D}\right)$ & $1 \mathrm{~s} 3 \mathrm{~d}$ & 186101.6 \\
\hline 5 & $\mathrm{He}\left({ }^{1} \mathrm{~S}\right)+\mathrm{He}\left({ }^{1} \mathrm{D}\right)$ & $1 \mathrm{~s} 3 \mathrm{~d}$ & 186105.0 \\
\hline 6 & $\mathrm{He}\left({ }^{1} \mathrm{~S}\right)+\mathrm{He}\left({ }^{1} \mathrm{P}\right)$ & $1 \mathrm{~s} 3 \mathrm{p}$ & 186209.4 \\
\hline 7 & $\mathrm{He}\left({ }^{1} \mathrm{~S}\right)+\mathrm{He}\left({ }^{1} \mathrm{~S}\right)$ & $1 \mathrm{~s} 2 \mathrm{~s}$ & 166277.5 \\
\hline 8 & $\operatorname{He}\left({ }^{1} \mathrm{~S}\right)+\mathrm{He}\left({ }^{3} \mathrm{~S}\right)$ & $1 \mathrm{~s} 2 \mathrm{~s}$ & 159856 \\
\hline 9 & $\mathrm{He}\left({ }^{1} \mathrm{~S}\right)+\mathrm{He}\left({ }^{1} \mathrm{~S}\right)$ & $1 \mathrm{~s}^{2}$ & 0 \\
\hline
\end{tabular}


The exact identification of the high velocity atom products is difficult. Atom products with velocities in the range $(4,000-30,000) \mathrm{m} / \mathrm{s}$ are registered in just 7 channels (40 $\mu \mathrm{s}$ each) for the flight path of $1.227 \mathrm{~m}$. We observed peaks in this range of velocities but it is not possible to identify exactly if they are due to atom products in the metastable state $\mathrm{He}$ $\left({ }^{1} \mathrm{~S} ; 1 \mathrm{~s} 2 \mathrm{~s}\right)$ or $\mathrm{He}\left({ }^{3} \mathrm{~S} ; 1 \mathrm{~s} 2 \mathrm{~s}\right)$ or $\mathrm{He}\left({ }^{1} \mathrm{~S} ; 1 \mathrm{~s}^{2}\right)$. An improvement of the resolution in this range of velocities requires a longer flight path.

In the following tables are presented experimental results on Dissociative Recombination of helium molecular ion. The initial rovibrational states of the parent molecular ion are given in the first two columns. The third column represent the theoretical velocity calculated using the formula (III.4.1). In column four are given the experimental observations. 
In Table II are listed the theoretical and experimental velocities of the product atoms yielded in the DR process of helium molecular ion from various rovibrational states to the $\mathrm{He}\left({ }^{3} \mathrm{~S} ; 1 \mathrm{~s} 3 \mathrm{~s}\right)$ atomic level at $183236.9 \mathrm{~cm}^{-1}$.

Table II:

\begin{tabular}{|c|c|c|c|}
\hline $\begin{array}{c}\text { Vibrational } \\
\text { quantum } \\
\text { number }\end{array}$ & $\begin{array}{c}\text { Rotational } \\
\text { quantum } \\
\text { number }\end{array}$ & $\begin{array}{c}\text { Theoretical } \\
\text { velocity }(\mathrm{m} / \mathrm{s})\end{array}$ & Experimental velocity $(\mathrm{m} / \mathrm{s})$ \\
\hline 3 & 0 & 286 & $350.1 \pm 2.6$ \\
\hline 3 & 1 & 346 & $432 \pm 11.5$ \\
\hline 3 & 2 & 443.4 & $545 \pm 12$ \\
\hline 3 & 3 & 558.5 & $797 \pm 12.6$ \\
\hline 3 & 4 & 682.2 & $946 \pm 8.65$ \\
\hline 3 & 5 & 810.5 & $1066 \pm 2.74$ \\
\hline 3 & 6 & 941 & - \\
\hline 3 & 7 & 1074 & 1346 \\
\hline 3 & 8 & 1207 & \\
\hline 3 & 538 & & \\
\hline & & & \\
\hline
\end{tabular}


In Table III are listed the theoretical and experimental velocities of the product atoms yielded in the DR process of helium molecular ion from various rovibrational states to the $\mathrm{He}\left({ }^{1} \mathrm{~S} ; 1 \mathrm{~s} 3 \mathrm{~s}\right)$ atomic level at $184864.9 \mathrm{~cm}^{-1}$.

Table III

\begin{tabular}{|c|c|c|c|}
\hline $\begin{array}{c}\text { Vibrational } \\
\text { quantum } \\
\text { number }\end{array}$ & $\begin{array}{c}\text { Rotational } \\
\text { quantum } \\
\text { number }\end{array}$ & $\begin{array}{c}\text { Theoretical } \\
\text { velocity }(\mathrm{m} / \mathrm{s})\end{array}$ & \begin{tabular}{c} 
Experimental velocity $(\mathrm{m} / \mathrm{s})$ \\
\hline 3
\end{tabular} \\
\hline 3 & 16 & 581 & - \\
\hline 4 & 6 & 481 & $700 \pm 5.5$ \\
\hline 4 & 7 & 699.5 & - \\
\hline 4 & 8 & 885 & 1051 \\
\hline 4 & 9 & 1055 & - \\
\hline 4 & 10 & 1215 & 1370 \\
\hline 4 & 11 & 1364 & $101.4 \pm 7.6$ \\
\hline 5 & 5 & 99.3 & \\
\hline
\end{tabular}


In Table IV are listed the expected and experimental velocities of the product atoms yielded in the DR process of helium molecular ion from various rovibrational states to the $\mathrm{He}\left({ }^{3} \mathrm{P} ; 1 \mathrm{~s} 3 \mathrm{p}\right)$ atomic level at $185564.6 \mathrm{~cm}^{-1}$.

\section{Table IV}

\begin{tabular}{|c|c|c|c|}
\hline $\begin{array}{c}\text { Vibrational } \\
\text { quantum } \\
\text { number }\end{array}$ & $\begin{array}{c}\text { Rotational } \\
\text { quantum } \\
\text { number }\end{array}$ & $\begin{array}{c}\text { Theoretical } \\
\text { velocity }(\mathrm{m} / \mathrm{s})\end{array}$ & \begin{tabular}{c} 
Experimental velocity (m/s) \\
\hline 4
\end{tabular} \\
\hline 4 & 13 & 831 & 835 \\
\hline 4 & 14 & 1093 & 1085 \\
\hline 5 & 0 & 1179 & 1192 \\
\hline 5 & 1 & 1194.6 & 1228 \\
\hline 5 & 2 & 1224 & - \\
\hline
\end{tabular}


In Table $\mathrm{V}$ are listed the theoretical and experimental velocities of the product atoms yielded in the DR process of helium molecular ion from various rovibrational states to the $\mathrm{He}\left({ }^{3} \mathrm{D} ; 1 \mathrm{~s} 3 \mathrm{~d}\right)$ atomic level at $186101.7 \mathrm{~cm}^{-1}$.

\section{Table V:}

\begin{tabular}{|c|c|c|c|}
\hline $\begin{array}{c}\text { Vibrational } \\
\text { quantum } \\
\text { number }\end{array}$ & $\begin{array}{c}\text { Rotational } \\
\text { quantum } \\
\text { number }\end{array}$ & $\begin{array}{c}\text { Theoretical } \\
\text { velocity }(\mathrm{m} / \mathrm{s})\end{array}$ & $\begin{array}{c}\text { Experimental velocity }(\mathrm{m} / \mathrm{s}) \\
\text { Standard deviation }\end{array}$ \\
\hline 5 & 3 & 49.6 & $51.1 \pm 2.34$ \\
\hline 5 & 4 & 381.3 & $387 \pm 10.5$ \\
\hline 5 & 5 & 568 & $751 \pm 4.2$ \\
\hline 5 & 6 & 732 & \\
\hline
\end{tabular}


In Table VI are listed the theoretical and experimental velocities of the product atoms yielded in the DR process of helium molecular ion from various rovibrational states to the $\mathrm{He}\left({ }^{1} \mathrm{D} ; 1 \mathrm{~s} 3 \mathrm{~d}\right)$ atomic level at $186105.1 \mathrm{~cm}^{-1}$.

Table VI:

\begin{tabular}{|c|c|c|c|}
\hline $\begin{array}{c}\text { Vibrational } \\
\text { quantum } \\
\text { number }\end{array}$ & $\begin{array}{c}\text { Rotational } \\
\text { quantum } \\
\text { number }\end{array}$ & $\begin{array}{c}\text { Theoretical } \\
\text { velocity }(\mathrm{m} / \mathrm{s})\end{array}$ & $\begin{array}{c}\text { Experimental velocity }(\mathrm{m} / \mathrm{s}) \\
\text { Standard deviation }\end{array}$ \\
\hline 4 & 15 & 344 & $337 \pm 8.5$ \\
\hline 5 & 4 & 367.7 & $542 \pm 6.2$ \\
\hline 5 & 5 & 559 & $720 \pm 6.5$ \\
\hline 5 & 6 & 725.9 & - \\
\hline 5 & 7 & 880.6 & $995 \pm 12$ \\
\hline 5 & 8 & 1028 & $1162 \pm 9.8$ \\
\hline 5 & 9 & 1173 & \\
\hline
\end{tabular}


In Table VI are listed the theoretical and experimental velocities of the product atoms yielded in the DR process of helium molecular ion from various rovibrational states to the $\mathrm{He}\left({ }^{1} \mathrm{P} ; 1 \mathrm{~s} 3 \mathrm{p}\right)$ atomic level at $186209.5 \mathrm{~cm}^{-1}$.

Table VII:

\begin{tabular}{|c|c|c|c|}
\hline $\begin{array}{c}\text { Vibrational } \\
\text { quantum } \\
\text { number }\end{array}$ & $\begin{array}{c}\text { Rotational } \\
\text { quantum } \\
\text { number }\end{array}$ & $\begin{array}{c}\text { Theoretical } \\
\text { velocity }(\mathrm{m} / \mathrm{s})\end{array}$ & Experimental velocity $(\mathrm{m} / \mathrm{s})$ \\
\hline 5 & 5 & 39.7 & $39 \pm 0.92$ \\
\hline 5 & 6 & 463 & $663 \pm 4.17$ \\
\hline 5 & 7 & 680 & $861 \pm 13$ \\
\hline 5 & 8 & 864 & - \\
\hline 5 & 9 & 1031 & - \\
\hline 5 & 10 & 1190 & \\
\hline
\end{tabular}




\section{COMMENTS}

In [10] are presented calculated cross sections for the dissociative recombination of $\mathrm{He}_{2}{ }^{+}$ molecular ion in the energy range $0.1 \mathrm{meV}-2 \mathrm{meV}$. From Figure 4 can be seen that the DR cross section for the direct process increase sharply as the electron energy goes to zero. The aspect of the resonance structure strongly depends on the initial vibrational state of the molecular ion. This is seen in figure 6 where the resonance shapes are shown for $v=0$ and $v=4$ molecular vibrational level. The cross section for the DR of $v=5$ is not presented in [10]. Our experimental results show that $\mathrm{v}=5$ vibrational level is significantly populated at the temperature of $1150 \mathrm{~K}$. We have observed many lines which correspond to DR product atoms from $\mathrm{v}=5$ initial states. Analyzing the data taken using the sort flight path of $0.533 \mathrm{~m}$, we observed few lines which do not fit in the velocity set yielded by equation (III.4.1).

In Table VIII are presented the additional lines observed using the short flight path.

\section{Table VIII:}

\begin{tabular}{|c|c|}
\hline Velocity $(\mathrm{m} / \mathrm{s})$ & Width $(\mathrm{m} / \mathrm{s})$ \\
\hline 44.8 & 6.8 \\
\hline 126 & 9.2 \\
\hline 150 & 7.6 \\
\hline 179 & 13.7 \\
\hline
\end{tabular}


These results might be explained by the presence of some significant resonances in the cross section structure for the indirect process. For the $v=5$ initial state the cross section presents a resonance peak in the energy range $0.54 \mathrm{meV}-0.67 \mathrm{meV}$ with the center at approximately $0.61 \mathrm{meV}$ (which explain the broad line at $126 \mathrm{~m} / \mathrm{s}$ ). Another resonance peak seems to exist in the energy range $0.01 \mathrm{meV}-0.04 \mathrm{meV}$ with the center at 0.022 $\mathrm{meV}$ (the 44.8 line). In the electron energy range of about $0.8 \mathrm{meV}-0.99 \mathrm{meV}$ with the center at $0.88 \mathrm{meV}$ could be an other resonance peak.

For $v=4$ initial vibrational state, a resonance peak in the cross section for the indirect DR process might be in the energy range $0.8 \mathrm{meV}-0.99 \mathrm{meV}$ with the center at about 0.92 $\mathrm{meV}$. This resonance is not observed in the given cross section for $\mathrm{v}=4$ vibrational state.

A disagreement between the theoretical prediction in [10] and our experimental results concerns the final atom product states observed. Although the calculations presented do not explicitly determine the final states, certain predictions can be made from asymptotic correlations of the three Dissociative states involved (figure 3 ). All correlate with one atom in the $\mathrm{He}\left(1 \mathrm{~s}^{2} ;{ }^{1} \mathrm{~S}\right)$ ground state and the other one in an excited state $\mathrm{He}\left(1 \mathrm{~s} 2 \mathrm{~s} ;{ }^{3} \mathrm{~S}\right)$ for the ${ }^{3} \Sigma_{g}^{+}$state; $\mathrm{He}\left(1 \mathrm{~s} 2 \mathrm{~s} ;{ }^{1} \mathrm{~S}\right)$ for the ${ }^{1} \Sigma_{g}^{+}$state and finally $\mathrm{He}\left(1 \mathrm{~s} 2 \mathrm{p} ;{ }^{3} \mathrm{P}\right)$ for the ${ }^{3} \Pi_{u}$ dissociative state. We observed experimentally additional states given in Table I. The origin of this disagreement could be the omission in the theoretical calculation of other possible dissociation paths. 


\section{CONCLUSIONS}

Using the short flight path of $0.533 \mathrm{~m}$ we identified a few additional broadened lines which do not match the lines yielded by the direct DR process. We possibly did not observe these broadened lines on the long flight path possibly because of their low intensity. These lines could be explained as being produced in the indirect DR process when the dissociation proceeds through intermediate Rydberg series states. The MCQDT theory predicts different shapes for the cross section curves for the direct and indirect process. The cross section curve for the direct process is smooth and shows increasing values as the incident electron's energy goes to zero. The cross section curve for the indirect process present sharp resonances in form of dips or peaks depending on the initial vibrational state of the molecular ion. Our experimental results shows the existence of such resonances. We can observe only those resonances for which the cross section for the indirect DR process is comparable to the value of the cross section for the direct DR process at zero energy for the incident electron.

Our experimental results on Dissociative Recombination of helium molecular ion $\mathrm{He}_{2}{ }^{+}$ shows the following final states for the DR product atoms: $\mathrm{He}\left({ }^{3} \mathrm{~S} ; 1 \mathrm{~s} 3 \mathrm{~s}\right), \mathrm{He}\left({ }^{1} \mathrm{~S} ; 1 \mathrm{~s} 3 \mathrm{~s}\right)$, $\mathrm{He}\left({ }^{3} \mathrm{P} ; 1 \mathrm{~s} 3 \mathrm{p}\right), \mathrm{He}\left({ }^{3} \mathrm{D} ; 1 \mathrm{~s} 3 \mathrm{~d}\right), \operatorname{He}\left({ }^{1} \mathrm{D} ; 1 \mathrm{~s} 3 \mathrm{~d}\right), \operatorname{He}\left({ }^{1} \mathrm{P} ; 1 \mathrm{~s} 3 \mathrm{p}\right), \operatorname{He}\left({ }^{3} \mathrm{~S} ; 1 \mathrm{~s} 2 \mathrm{~s}\right), \operatorname{He}\left({ }^{1} \mathrm{~S} ; 1 \mathrm{~s} 2 \mathrm{~s}\right)$ and possibly $\mathrm{He}\left({ }^{1} \mathrm{~S} ; 1 \mathrm{~s}^{2}\right)$. Results similar to ours were obtained in experiments done using optical methods [5]. Experimental results from the DR of helium molecular ion clearly shows the final product atoms in excited states $3^{3} \mathrm{~S}$ and $3^{3} \mathrm{D}$. The theoretical model [10] predicts only $n=2$ manifold states. Further theoretical modeling for this complex process is required. 


\section{REFERENCES}

[1] J. Geo. Res. Vol. 101,A2 2435, (1996)

[2] T. Torgersen, Chem. Geol., 79, 1, (1989)

[3] G. Kockarts, Space Sci. Rev., 14, 723, (1973)

[4] D.R.Bates, Comments At. Mol. Phys. 5, 89, (1976)

[5] V. A Ivanov, N. P. Penkin, Yu. E. Skoblo Opt. Spectrosc. (URSS) 54 (5) 552 (1983)

[6] J.N. Bardsley, J. Phys. B ,ser. 2, Vol. 1, 365, (1968)

[7] D.R. Bates, Phys. Rev., 89, 492-3, (1950)

[8] T.R. Connor, M.A. Biondi, Phys. Rev., 140, A778-83, (1965)

[9]J. S. Cohen, Phys. Rev., 13, 1, 86, (1976)

[10] L. Carata, A. E. Orel. A Suzor-Weiner, Phys. Rev. A, 59,4,2804 (1999)

[11] H.F.Wellenstein, W.W. Robertson, J. Chem. Phys. 56, 3, 1077 (1972)

[12] R.S. Mulliken Phys. Rev. 136, 4A, A 962 (1964)

[13] C.C Lin R.M. S. John, Phys. Rev. 128,4,1749 (1962)

[14] G.B. Ramos, M. Schlamkowitz, J. Sheldon, K.A. Hardy and J.R. Peterson Phys. Rev. A 52, 4556(1995)

[15] J.R. Peterson, K.A. Hardy, "Dissociative Recombination:Theory, Experiment, and Applications" (World Scientific Publishing Co.,Singapore, 1989)

[16] K.A. Hardy, E. Gillman and J. Sheldon, J. Appl. Phys. 67,7240(1990).

[17] L. Coman, M. Guna, L. Simons and K. Hardy, Phys. Rev. Lett., 83, 14, 2715 (1999)

[18] A Giusti, J. Phys. B, 13, 3867-3849, (1980)

[19] S. L. Guberman, A. Giusti- Suzor, J. Chem. Phys., 95 (4) 2602, (1991)

[20] P.M. Dehmer, W.A. Chupka, J. Chem. Phys., 65, 6, 2243, (1976) 
[21] R. Colle, J. Chem. Phys., 74, 5, 2910, (1981)

[22] M.J. Seaton, Proc. Phys. Soc. London 88, 801, (1966)

[23] A. Giusti-Suzor, Ch. Jungen, J. Chem. Phys. 83, 3, 986, (1983)

[24] F.H. Mies, Molec. Phys., 14, 5, 953, (1980)

[25] G. Herzberg, Molecular Spectra and Molecular Structure, 66-145, (1950)

[26] M. H. Schlamkowitz, Master Thesis: "A more accurate determination of the binding ehergy of $\mathrm{AR}_{2}{ }^{+}$and Observations of Dissociative Recombination in Argon and Neon", Florida International University, 1994

[27] J. Sebastian Oddone, Master Thesis: "Dissociative Recombination of $\mathrm{N}_{2}^{+}$", Florida International University, 1998

[28] K.K. Sunil, J. Lin, H. Siddiqui, P. E. Siska, and K.D. Jordan, J. Chem. Phys. 78, $6190(1983)$ 


\section{APPENDIX 1}

FORTRAN CODE TO CALCULATE THE VELOCITIE OF THE FINAL PRODUCTS OF DR

\section{IMPLICIT NONE}

REAL We,WeXe,Le,Be,M,Dm0,Ev,Er, Efs,k,En,s

INTEGER $\mathrm{v}, \mathrm{j}$

DO $30 \mathrm{a}=1,20$

WRITE $(*, *)$ 'Input the energy of the final state'

$\operatorname{READ}(*, *) \operatorname{Efs}$

WRITE $(*, *)$ 'Input the maximum vibrational level'

$\operatorname{READ}(*, *) \mathrm{p}$

WRITE $(*, *)$ 'Input the maximum rotational level'

$\operatorname{READ}(*, *) \mathrm{t}$

$\mathrm{We}=1698.5$

$\mathrm{WeXe}=35.3$

$\mathrm{Le}=.224$

$\mathrm{Be}=7.221$

$\mathrm{M}=8065.47$

$\mathrm{Dm} 0=2.4457 * \mathrm{M}+0.5 * \mathrm{We}-0.25 * \mathrm{WeXe}$

$\mathrm{Ei}=198310.77$

WRITE $(*, *)$ 'D0=',Dm0 


$$
\begin{aligned}
& \text { DO } 5 \mathrm{v}=4, \mathrm{p}, 1 \\
& \text { DO } 10 \mathrm{j}=1, \mathrm{t}, 1 \\
& \text { c } \quad \operatorname{Evarray}(v)=150000 \\
& \mathrm{Ev}=\mathrm{We} *(\mathrm{v}-1+.5)-\mathrm{WeXe} *(\mathrm{v}-1+.5) * * 2 \\
& \text { c } \quad \text { WRITE }(*, *)^{\prime} \operatorname{Ev}(', v, ')={ }^{\prime}, \mathrm{Ev} \\
& \mathrm{Er}=\left(\operatorname{Be}-\mathrm{Le}^{*}(\mathrm{v}-1+.5)\right) *(\mathrm{j}) *(\mathrm{j}-1)-.00051^{*}((\mathrm{j}-1) * * 2) *(\mathrm{j}) * * 2 \\
& \text { c } \quad \text { WRITE }\left(*,{ }^{*}\right){ }^{\prime} \operatorname{Er}\left(', j,{ }^{\prime}\right)={ }^{\prime}, \operatorname{Er} \\
& \mathrm{k}=(\mathrm{Ei}-\mathrm{Dm} 0+\mathrm{Ev}+\mathrm{Er}-\mathrm{Efs}) / \mathrm{M} \\
& \mathrm{En}=\mathrm{k} * \mathrm{M} \\
& \text { IF (k .LT. 0) THEN }
\end{aligned}
$$$$
\text { WRITE }(*, *)^{\prime} \text { this final state cannot be reach' }
$$$$
\text { ELSE IF (k.GT.0) THEN }
$$$$
\mathrm{s}=10000 * \operatorname{sqrt}\left(\mathrm{k}^{*}(.240939)\right)
$$$$
\text { OPEN (UNIT=15,FILE='err1.doc',STATUS='old') }
$$$$
\text { WRITE }(15,20) s, v-1, j-1, E v, E r, E f s
$$$$
20 \text { FORMAT(1X,f12.4,2I8,3F12.3) }
$$$$
\text { END IF }
$$$$
\text { c } \quad \text { WRITE }(*, *) \text { 'Velocity }=\text { ',s }
$$

10 CONTINUE

5 CONTINUE

30 CONTINUE

END 
Velocity

$(\mathrm{m} / \mathrm{s})$

39.7

49.6

99.3

286.0

343.9

346.0

358.3

367.6

381.1

443.4

463.6

472.7

481.1

558.4

559.8

568.8

680.8

682.2

699.5

725.8

732.8

810.5

832.4

864.1

880.5

885.1

886.3

941.6

1028.9

1031.7

1033.8

1055.0

1074.1

1093.6

1173.2

1177.5

1179.9

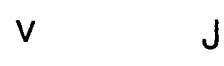

5

5

4

3

4

3

4

5

5

3

5

4

4

3

5

5

5

3

4

5

5

3

4

5

5

4

5

3

5

5

5

4

3

4

5

5

5

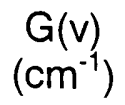

$\mathrm{F}(\mathrm{J})$
$\left(\mathrm{cm}^{-1}\right)$

8278.5

8278.5

6930.0

5511.9

6930.0

5511.9

6930.0

8278.5

8278.5

5511.9

8278.5

6930.0

6930.0

5511.9

8278.5

8278.5

8278.5

5511.9

6930.0

8278.5

8278.5

5511.9

6930.0

8278.5

8278.5

6930.0

8278.5

5511.9

8278.5

8278.5

8278.5

6930.0

5511.9

6930.0

8278.5

8278.5

8278.5
Energy of the

Final State $\left(\mathrm{cm}^{-1}\right)$

186209.5

186101.7

184864.9

183236.9

186105.1

183236.9

186101.7

186105.1

186101.7

183236.9

186209.5

185564.7

184864.9

183236.9

186105.1

186101.7

186209.5

183236.9

184864.9

186105.1

186101.7

183236.9

185564.7

186209.5

186105.1

184864.9

186101.7

183236.9

186105.1

186209.5

186101.7

184864.9

183236.9

185564.7

186105.1

186101.7

185564.7 


\begin{tabular}{|c|c|c|c|c|c|}
\hline $\begin{array}{c}\text { Velocity } \\
(\mathrm{m} / \mathrm{s})\end{array}$ & v & $J$ & $\begin{array}{l}\mathrm{G}(\mathrm{v}) \\
\left(\mathrm{cm}^{-1}\right)\end{array}$ & $\begin{array}{c}\mathrm{F}(\mathrm{J}) \\
\left(\mathrm{cm}^{-1}\right)\end{array}$ & $\begin{array}{l}\text { Energy of the } \\
\text { Final State } \\
\left(\mathrm{cm}^{-1}\right)\end{array}$ \\
\hline 1190.1 & 5 & 10 & 8278.5 & 652.9 & 186209.5 \\
\hline 1194.9 & 5 & 1 & 8278.5 & 12.0 & 185564.7 \\
\hline 1207.7 & 3 & 8 & 5511.9 & 461.0 & 183236.9 \\
\hline 1215.9 & 4 & 10 & 6930.0 & 677.6 & 184864.9 \\
\hline 1224.5 & 5 & 2 & 8278.5 & 35.9 & 185564.7 \\
\hline 1267.5 & 5 & 3 & 8278.5 & 71.8 & 185564.7 \\
\hline 1314.6 & 5 & 10 & 8278.5 & 652.9 & 186105.1 \\
\hline 1316.3 & 4 & 15 & 6930.0 & 1462.5 & 185564.7 \\
\hline 1318.5 & 5 & 10 & 8278.5 & 652.9 & 186101.7 \\
\hline 1322.7 & 5 & 4 & 8278.5 & 119.6 & 185564.7 \\
\hline 1341.8 & 3 & 9 & 5511.9 & 575.5 & 183236.9 \\
\hline 1342.4 & 5 & 11 & 8278.5 & 782.1 & 186209.5 \\
\hline 1370.7 & 4 & 11 & 6930.0 & 811.6 & 184864.9 \\
\hline 1388.4 & 5 & 5 & 8278.5 & 179.3 & 185564.7 \\
\hline 1454.0 & 5 & 11 & 8278.5 & 782.1 & 186105.1 \\
\hline 1457.4 & 5 & 11 & 8278.5 & 782.1 & 186101.7 \\
\hline 1463.3 & 5 & 6 & 8278.5 & 250.8 & 185564.7 \\
\hline 1476.1 & 3 & 10 & 5511.9 & 702.2 & 183236.9 \\
\hline 1490.4 & 5 & 12 & 8278.5 & 922.3 & 186209.5 \\
\hline 1521.2 & 4 & 12 & 6930.0 & 957.3 & 184864.9 \\
\hline 1545.9 & 5 & 7 & 8278.5 & 334.0 & 185564.7 \\
\hline 1591.6 & 5 & 12 & 8278.5 & 922.3 & 186105.1 \\
\hline 1594.7 & 5 & 12 & 8278.5 & 922.3 & 186101.7 \\
\hline 1610.6 & 3 & 11 & 5511.9 & 841.2 & 183236.9 \\
\hline 1634.9 & 5 & 8 & 8278.5 & 428.8 & 185564.7 \\
\hline 1635.0 & 5 & 13 & 8278.5 & 1073.7 & 186209.5 \\
\hline 1668.3 & 4 & 13 & 6930.0 & 1114.4 & 184864.9 \\
\hline 1727.7 & 5 & 13 & 8278.5 & 1073.7 & 186105.1 \\
\hline 1729.4 & 5 & 9 & 8278.5 & 535.1 & 185564.7 \\
\hline 1730.7 & 5 & 13 & 8278.5 & 1073.7 & 186101.7 \\
\hline 1745.1 & 3 & 12 & 5511.9 & 992.2 & 183236.9 \\
\hline 1777.0 & 5 & 14 & 8278.5 & 1235.8 & 186209.5 \\
\hline 1812.8 & 6 & 0 & 9557.3 & 0.0 & 186209.5 \\
\hline 1812.9 & 4 & 14 & 6930.0 & 1282.9 & 184864.9 \\
\hline 1822.2 & 6 & 1 & 9557.3 & 11.5 & 186209.5 \\
\hline 1828.3 & 5 & 10 & 8278.5 & 652.9 & 185564.7 \\
\hline 1841.0 & 6 & 2 & 9557.3 & 34.6 & 186209.5 \\
\hline 1862.7 & 5 & 14 & 8278.5 & 1235.8 & 186105.1 \\
\hline 1865.4 & 5 & 14 & 8278.5 & 1235.8 & 186101.7 \\
\hline 1866.2 & 5 & 0 & 8278.5 & 0.0 & 184864.9 \\
\hline 1868.9 & 6 & 3 & 9557.3 & 69.1 & 186209.5 \\
\hline
\end{tabular}




$\begin{array}{cccccc}\begin{array}{c}\text { Velocity } \\ (\mathrm{m} / \mathrm{s})\end{array} & \mathrm{V} & \mathrm{J} & \begin{array}{c}\mathrm{G}(\mathrm{V}) \\ \left(\mathrm{cm}^{-1}\right)\end{array} & \begin{array}{c}\mathrm{F}(\mathrm{J}) \\ \left(\mathrm{cm}^{-1}\right)\end{array} & \begin{array}{c}\text { Energy of the } \\ \text { Final State } \\ \left(\mathrm{cm}^{-1}\right)\end{array} \\ 1875.7 & & & & & \\ 1879.4 & 5 & 1 & 8278.5 & 12.0 & 184864.9 \\ 1894.7 & 5 & 13 & 5511.9 & 1155.2 & 183236.9 \\ 1896.8 & 6 & 2 & 8278.5 & 35.9 & 184864.9 \\ 1899.5 & 6 & 0 & 9557.3 & 0.0 & 186105.1 \\ 1905.3 & 6 & 4 & 9557.3 & 0.0 & 186101.7 \\ 1905.9 & 6 & 1 & 9557.3 & 115.2 & 186209.5 \\ 1908.6 & 6 & 1 & 9557.3 & 11.5 & 186105.1 \\ 1916.8 & 5 & 15 & 8278.5 & 1408.7 & 186101.7 \\ 1922.8 & 5 & 3 & 8278.5 & 71.8 & 184864.9 \\ 1923.9 & 6 & 2 & 9557.3 & 34.6 & 186105.1 \\ 1926.5 & 6 & 2 & 9557.3 & 34.6 & 186101.7 \\ 1930.9 & 5 & 11 & 8278.5 & 782.1 & 185564.7 \\ 1949.8 & 6 & 5 & 9557.3 & 172.6 & 186209.5 \\ 1950.5 & 6 & 3 & 9557.3 & 69.1 & 186105.1 \\ 1953.1 & 6 & 3 & 9557.3 & 69.1 & 186101.7 \\ 1955.3 & 4 & 15 & 6930.0 & 1462.5 & 184864.9 \\ 1959.6 & 5 & 4 & 8278.5 & 119.6 & 184864.9 \\ 1985.5 & 6 & 4 & 9557.3 & 115.2 & 186105.1 \\ 1988.0 & 6 & 4 & 9557.3 & 115.2 & 186101.7 \\ 1996.5 & 5 & 15 & 8278.5 & 1408.7 & 186105.1 \\ 1999.0 & 5 & 15 & 8278.5 & 1408.7 & 186101.7 \\ 2001.8 & 6 & 6 & 9557.3 & 241.4 & 186209.5 \\ 2004.5 & 5 & 5 & 8278.5 & 179.3 & 184864.9 \\ 2013.5 & 3 & 14 & 5511.9 & 1329.9 & 183236.9 \\ 2028.2 & 6 & 5 & 9557.3 & 172.6 & 186105.1 \\ 2030.7 & 6 & 5 & 9557.3 & 172.6 & 186101.7 \\ 2036.5 & 5 & 12 & 8278.5 & 922.3 & 185564.7 \\ 2057.1 & 5 & 6 & 8278.5 & 250.8 & 184864.9 \\ 2060.6 & 6 & 7 & 9557.3 & 321.4 & 186209.5 \\ 2077.9 & 4 & 0 & 6930.0 & 0.0 & 183236.9 \\ 2078.2 & 6 & 6 & 9557.3 & 241.4 & 186105.1 \\ 2080.7 & 6 & 6 & 9557.3 & 241.4 & 186101.7 \\ 2086.8 & 4 & 1 & 6930.0 & 12.4 & 183236.9 \\ 2104.5 & 4 & 2 & 6930.0 & 37.3 & 183236.9 \\ 2116.6 & 5 & 7 & 8278.5 & 334.0 & 184864.9 \\ 2125.8 & 6 & 8 & 9557.3 & 412.7 & 186209.5 \\ 2130.8 & 4 & 3 & 6930.0 & 74.5 & 183236.9 \\ 2135.0 & 6 & 7 & 9557.3 & 321.4 & 186105.1 \\ 2137.4 & 6 & 7 & 9557.3 & 321.4 & 186101.7 \\ 2144.6 & 5 & 13 & 8278.5 & 1073.7 & 185564.7\end{array}$

